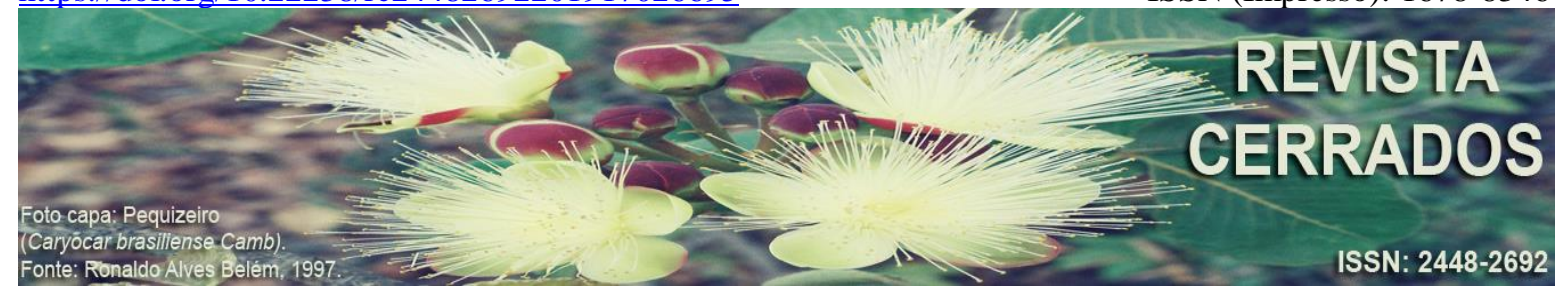

\title{
OS ESPAÇOS DA EXCLUSÃO SOCIAL NA CIDADE DE CAMPOS DOS GOYTACAZES - RJ
}

\section{THE SPACES OF SOCIAL EXCLUSION IN THE CITY OF CAMPOS DOS GOYTACAZES-RJ}

\section{LOS ESPACIOS DE EXCLUSIÓN SOCIAL EN LA CIUDAD DE CAMPOS DOS GOYTACAZES-RJ}

\author{
Glaucia de Oliveira Claudio \\ Universidade Federal Fluminense - UFF \\ E-mail: <glaucia_lv@hotmail.com>. \\ Leandro Bruno Santos \\ Universidade Federal Fluminense - UFF \\ E-mail: <leandrobruno@id.uff.br>.
}

\begin{abstract}
RESUMO
Vivemos um momento marcado pela revalorização do território e sua utilização na análise e implementação de políticas públicas, sobretudo políticas sociais. Este texto aborda os processos de exclusão social, pobreza e desigualdade na cidade de Campos dos Goytacazes. Trata-se de uma cidade importante na rede urbana do estado do Rio de Janeiro, constituindose num polo regional relevante na oferta de comércio e serviços. Juntamente com outras cidades do Norte Fluminense, Campos dos Goytacazes também tem sido utilizada como suporte para as atividades de exploração de petróleo na Bacia de Campos. Apesar de sua importância e da dinâmica econômica, a cidade é marcada por uma elevada exclusão social que, no tecido urbano, apresenta uma expressão territorial. Neste texto, pretendemos abordar a desigualdade sob a ótica da exclusão social, buscando contribuir com a produção e a leitura de indicadores sociais territorializados da Cidade de Campos dos Goytacazes - RJ, dando visibilidade às áreas de inclusão e exclusão social, por meio da espacialização dos dados secundários dos dois últimos censos demográficos (2000 e 2010) disponibilizados pelo Instituto Brasileiro de Geografia e Estatística (IBGE). Com base nos indicadores, espacializamos os dados e verificamos a concentração de setores marcados pela elevada exclusão ao norte da cidade, tendo como grande divisor o Rio Paraíba do Sul.
\end{abstract}

Palavras-chave: Desigualdade, exclusão social, Campos dos Goytacazes. 
CLAUDIO, G. O.; SANTOS, L. B.

Os espaços da exclusão social na cidade de Campos dos Goytacazes - RJ

\begin{abstract}
We live in a moment marked by the revaluation of the territory and its use in the analysis and implementation of public policies, especially social policies. This text addresses the processes of social exclusion, poverty and inequality in the city of Campos dos Goytacazes. It is an important city in the urban network of the state of Rio de Janeiro, constituting a relevant regional center in the supply of trade and services. Like other cities in Norte Fluminense, Campos dos Goytacazes has also been used as support for oil exploration activities in the Campos Basin. Despite its importance and economic dynamics, the city is marked by a high social exclusion that, in the urban space, has a territorial expression. In this text, we intend to address inequality from the perspective of social exclusion, seeking to contribute to the production and reading of territorialized social indicators of Campos dos Goytacazes - RJ, giving visibility to the areas of social inclusion and exclusion, through the spatialization of secondary data from the last two demographic censuses (2000 and 2010) provided by the Brazilian Institute of Geography and Statistics (IBGE). Based on the indicators, we spatialized the data and verified the concentration of sectors marked by the high exclusion to the north of the city, having as great divide the Paraíba do Sul River.
\end{abstract}

Keywords: Inequality, social exclusion, Campos dos Goytacazes.

\title{
RESUMEN
}

Hemos vivido un momento marcado por la revaluación del territorio y su uso en el análisis e implementación de políticas públicas, especialmente de las políticas sociales. Este texto aborda los procesos de exclusión social, pobreza y desigualdad en la ciudad de Campos dos Goytacazes. Es una ciudad importante en la red urbana del estado de Río de Janeiro, constituyendo un centro regional relevante en el suministro de comercio y servicios. Al igual que otras ciudades en Norte Fluminense, Campos dos Goytacazes también ha sido utilizada para apoyar actividades de exploración petrolera en la cuenca de Campos. A pesar de su importancia y dinámica económica, la ciudad ha sido marcada por una alta exclusión social que, en el tejido urbano, tiene una expresión territorial. En este texto, intentamos abordar la desigualdad desde la perspectiva de la exclusión social, buscando contribuir a la producción y lectura de indicadores sociales territorializados de Campos dos Goytacazes - RJ, dando visibilidad a las áreas de inclusión y exclusión social, a través de la espacialización de los datos secundarios de los últimos dos censos demográficos (2000 y 2010) divulgados por el Instituto Brasileño de Geografía y Estadística (IBGE). Con base en los indicadores, espacializamos los datos y verificamos la concentración de sectores marcados por la alta exclusión al norte de la ciudad, teniendo como gran división el río Paraíba do Sul.

Palabras clave: Desigualdad, exclusión social, Campos dos Goytacazes.

\section{INTRODUÇÃO}

Problemas como desigualdade e exclusão social são fortemente interligados e, em países com grande dimensão territorial como o Brasil, são importantes para entendermos as Revista Cerrados, Montes Claros/MG, v.17, n. 2, p. 66-95, jul./dez.-2019. 
CLAUDIO, G. O.; SANTOS, L. B.

Os espaços da exclusão social na cidade de Campos dos Goytacazes - RJ

condições de vida e cidadania. Tais dimensões engendram maior diversidade territorial, de modo que os fenômenos assumem características específicas em cada lugar. Ao mesmo tempo, são também encontrados traços gerais do movimento da formação sócio-espacial brasileira, entre elas a desigualdade social. Neste texto, realizaremos um debate ao redor da leitura de processos de inclusão e exclusão social, pobreza e desigualdade em cidades médias.

Para Carvalho (2003, p. 5), “tomar a exclusão social como eixo articulador das diversas questões decorrentes das desigualdades sociais é reconhecer a íntima imbricação das precárias condições de vida de amplos segmentos sociais". A exclusão social acompanha, indissociavelmente, o crescimento das cidades médias, carregando consigo todo caráter de desigualdade social. Para Schwartzman (2004, p. 35), a pobreza é uma "combinação de heranças, condições e escolhas de natureza econômica, política e cultural". Por não terem conhecimento dos seus direitos e deveres, grande parte da população fica à mercê deste jogo de poder que domina o espaço e exclui os mais pobres dos seus direitos a uma qualidade de vida de forma digna, tirando do seu controle o poder de fazer cumprir sua cidadania.

Nesse contexto, utilizaremos como recorte espacial o município de Campos dos Goytacazes, situado ao norte do Estado do Rio de Janeiro, contando com 4.026,696 km² de extensão e 463.731 habitantes, dos quais 418.565 são urbanos e o restante, 44.166, residentes no espaço rural, exibindo uma densidade populacional de $114,65 \mathrm{hab} / \mathrm{km}^{2}$ (mapa 1).

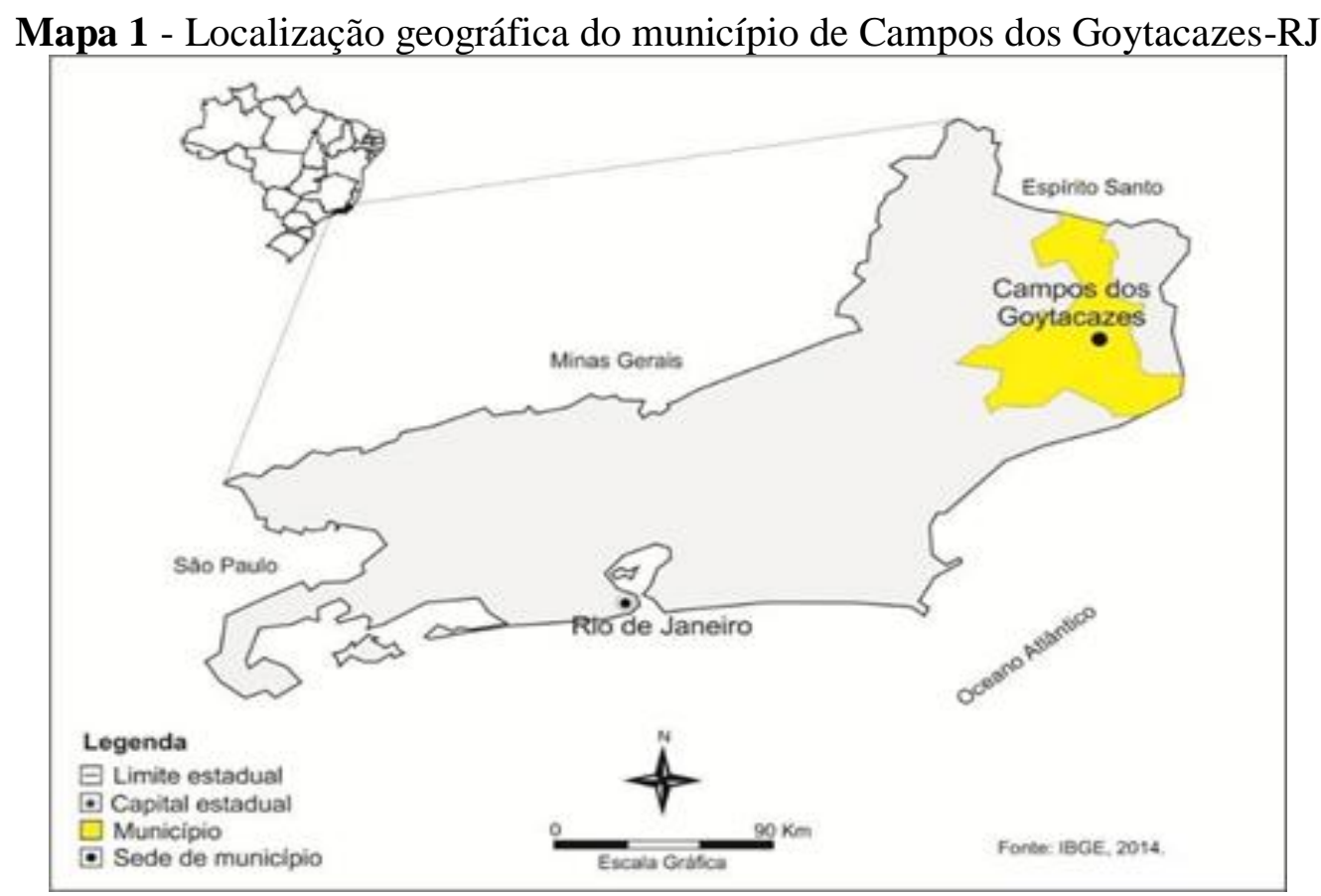

Fonte: IBGE, 2014. 
CLAUDIO, G. O.; SANTOS, L. B.

Os espaços da exclusão social na cidade de Campos dos Goytacazes - RJ

Com este trabalho, buscaremos contribuir com a produção e a leitura de indicadores sociais territorializados da cidade de Campos dos Goytacazes, dando visibilidade às áreas de inclusão e exclusão social. A identificação das áreas de exclusão e inclusão social será feita por meio do levantamento de dados secundários e construção de indicadores sociais, fazendo uso dos censos disponibilizados pelo Instituto Brasileiro de Geografia e Estatística (IBGE), por setores censitários

Para fins de levantamento dos dados, distribuímos nossas variáveis em quatro indicadores: I. Demografia (média de pessoas por domicílio por setor), II. Educação (taxa de analfabetismo de 10 a 14 anos, \% de chefes de família com baixa escolaridade -4 anos de estudos); III. Economia (chefes de família com renda de até 2 salários mínimos, chefes de família sem rendimento, chefes de família com 20 ou mais salários mínimos); IV. Ambiente (\% de domicílios sem banheiro, \% de domicílios com 4 banheiros ou mais, \% de domicílios ligados à rede de esgoto) $)^{1}$.

O recorte temporal de dois censos do IBGE (2000 e 2010) permite identificar e verificar se houve mudanças nas áreas de inclusão e exclusão social, mediante representação cartográfica dos setores censitários. A partir da produção de mapas temáticos, esperamos contribuir com a produção de indicadores sociais territorializados e a elaboração de políticas públicas, mediante a elaboração de mapas de exclusão social, por variável selecionada, desenvolvidos com o uso de softwares livres (Qgis e Philcarto).

Além desta introdução, o artigo está estruturado em outras seis partes. $\mathrm{Na}$ sequência, realizamos uma discussão ampla em torno da desigualdade social para, em seguida, tratar da exclusão social. Na terceira parte, delineamos o contexto social e econômico de Campos dos Goytacazes. Na quarta parte, apresentamos os indicadores selecionados e identificamos os espaços de exclusão social em Campos. Ao final, constam as considerações finais e as referências utilizadas no trabalho.

\section{Exclusão social, desigualdade: uma visão ampla}

Sabemos que o desemprego tem sido um dos impactos que mais refletem as condições de desigualdade e exclusão social que vêm sendo acentuadas não somente em países desenvolvidos, mas também naqueles que adotaram uma série de reformas ou rodadas

\footnotetext{
${ }^{1}$ Trata-se de metodologia desenvolvida por Martinuci (2016). Revista Cerrados, Montes Claros/MG, v.17, n. 2, p. 66-95, jul./dez.-2019.
} 
CLAUDIO, G. O.; SANTOS, L. B.

Os espaços da exclusão social na cidade de Campos dos Goytacazes - RJ

de neoliberalização (BRENNER; PECK; THEODORE, 2012) favoráveis ao capital estrangeiro em seus territórios, como é o caso dos países periféricos.

O desemprego tem relação com o processo de globalização econômica (SINGER, 1999). A globalização, amplamente disseminada e defendida como portadora de facilidades de acessos e oportunidades, traz implicações nada positivas, a partir do momento que são analisados também os seus impactos sociais e territoriais, que surgem a partir do momento em que empresas de países hegemônicos vislumbram, em países periféricos, as vantagens de exploração do trabalho e da legislação mais flexível, onde a mão de obra é abundante e os custos com salários são baixos.

Martins (1997) chama atenção para o fato que "o problema da exclusão nasce com a sociedade capitalista", não sendo produto, propriamente, de um projeto neoliberal. Este ganha força no Brasil como "um programa de desmonte do Estado clientelista e patrimonialista", especialmente a partir dos anos 1990. Apesar de seu papel no aumento da exclusão social, com a diminuição do papel do Estado na redução das disparidades, é preciso ter como pano de fundo a "sociedade que tem como lógica própria tudo desenraizar e a todos excluir porque tudo deve ser lançado no mercado; para que tudo e todos sejam lançados às leis de mercado" (MARTINS, 1997, p. 30).

O sistema capitalista que exclui a todos em algum momento é o mesmo que vai incluir a sociedade, num outro momento, sob uma lógica capitalista que atenda aos seus interesses. E, quando analisada a atual sociedade brasileira, notamos que a mesma se encontra num quadro de exclusão não apenas do que diz respeito a uma economia moderna, mas também excluída de serviços públicos, ocasionando processos de exclusão social e econômicos que "tendem a ser muito mais violentos e traumáticos do que situações de inclusão limitada" (SCHWARTZMAN, 2004, p. 31).

Essa lógica de exclusão e posterior inclusão tem a ver com a circulação do capital, em que são necessárias algumas condições para sua reprodução enquanto sistema econômico, tais como tendência de disseminação da propriedade privada, assalariamento, controle da natureza, entre outros. Esse processo é denominado, por Smith (1988), de tendência de igualização, sendo uma das principais responsáveis pelo desenvolvimento desigual do sistema econômico sobre o espaço.

Dialogando com Sposito (2004), vemos que, em países “periféricos”, no bojo da nova divisão internacional do trabalho, há a "internacionalização do capital”, desencadeando Revista Cerrados, Montes Claros/MG, v.17, n. 2, p. 66-95, jul./dez.-2019. 
CLAUDIO, G. O.; SANTOS, L. B.

Os espaços da exclusão social na cidade de Campos dos Goytacazes - RJ

uma desigualdade no que diz respeito ao comércio internacional, senão também relacionada aos processos de produção e distribuição. Nesses países, a descentralização do capital se faz presente por meio da realização de uma produção que, apesar de ser a mesma apresentada em países centrais, exibe desigualdades, tendo em vista que os retornos dos países "periféricos" em relação ao valor do que é produzido em seu território não se comparam com aqueles dos países centrais.

Segundo Martins (2002), o desemprego seria a situação social na qual o indivíduo encontra-se mais longe de alcançar o que seria essencial para que passe a fazer parte de uma sociedade que busca uma "igualdade jurídica", sem a qual não seria possível que suas forças de trabalho sejam comparadas à mercadoria, fazendo parte de um processo de produção que o torne vendedor de sua força de trabalho e se tornando parte de um processo de produção que cada vez mais exige qualificações, tornando-o "sujeito às injunções do mercado" (MARTINS, 2002, p. 28).

Martins (2002) relata que a exclusão social nos diz mais sobre as questões sociais do que sobre a economia, é algo que abrange muito mais do que a distribuição de renda, envolve a "distribuição equitativa de bens sociais", porém, estes bens acabam sendo distanciados de grande parte da população, a partir do momento em que o capitalismo, fazendo uso de suas forças, busca a expansão a qualquer custo, "debitando na conta do trabalhador e dos pobres o preço do processo sem ética, nem princípios, privatiza ganhos nesse caso injusto e socializa perdas, crises e problemas sociais" (MARTINS, 2002, p.11), criando situações precárias e, até mesmo, desumanas, do que seria uma inclusão criada pela mesma sociedade que exclui.

Este modo capitalista de produção tem apresentado certo enfraquecimento do Poder Estatal, cujas ações têm priorizado os grupos hegemônicos, formado por uma minoria dominante que detém controle sobre as dinâmicas territoriais. E no território brasileiro, marcado por uma dimensão continental, a cidadania estaria mais vinculada ao nível local, dando, assim, importância aos lugares como espaço vivido repleto de experiências e de trocas. Para Santos (2000, p. 55-56),

O território tanto quanto o lugar, são esquizofrênicos, porque de um lado acolhem os vetores da globalização, que neles se instalam para impor sua nova ordem, e, de outro lado, neles se produz uma contra-ordem, porque há uma produção acelerada de pobres, excluídos, marginalizados. 
CLAUDIO, G. O.; SANTOS, L. B.

Os espaços da exclusão social na cidade de Campos dos Goytacazes - RJ

Esta esquizofrenia ocorre porque cada agente social atua no lugar de acordo com sua perspectiva e realiza a comunicação com os demais por meio de técnica e produção na qual podem ocorrer ruídos entre as interações. Problemas são provocados pelo modelo de desenvolvimento capitalista, surtindo efeitos nas cidades, ocasionando problemas advindos de uma "urbanização acelerada nos países de economia dependente, e suas cidades manifestam todo tipo de problema, relacionados ao 'inchaço' populacional que vivem”' (SPOSITO, 2004, p. 70-71),

Nas grandes cidades, a falta de habitações, de água encanada, de esgotos, de creches, escolas, hospitais, transportes coletivos e até de áreas de lazer dão uma mostra ampliada das dificuldades que podem ser detectadas, ainda que em escala menor, até mesmo nas cidades de cinqüenta mil habitantes dos países de economia dependente (SPOSITO, 2004, p. 72).

Tais consequências aparecem nos centros urbanos, por meio do que Singer (1999) analisa como sendo uma das duas concepções que circundam a questão política em torno da exclusão social, que "pode ter causas individuais bem como estruturais" (SINGER, 1999, p. 65). Na concepção individualista, a exclusão social seria consequência das instituições que se opõem às atividades econômicas em prol dos trabalhadores. E cabe ao indivíduo buscar seu sucesso, logo, seu fracasso também estaria de acordo com suas escolhas. Enquanto os estruturalistas, baseados nas perspectivas marxistas e keynesianistas, acreditam que há um jogo econômico que produz vencedores e perdedores, sendo a desigualdade um processo decorrente da economia. Para amenizá-lo, seria necessário um equilíbrio justo de renda direta ou indiretamente -, não isentando do Estado a responsabilidade, já que, para os estruturalistas, o capitalismo estaria longe de buscar tal inclusão social. Com isso, “[...] ambas as concepções são importantes. Estruturas sociais e econômicas assim como as instituições importam e o comportamento individual também” (SINGER, 1999, p. 82).

\section{Sob a ótica da exclusão social}

Martins (1997) propõe que, ao usarmos o termo exclusão, precisamos levar em conta que tal termo abrange uma gama de problemas que são camuflados e levados à redução, numa generalidade que abrange todo e qualquer problema que envolva a sociedade. $\mathrm{O}$ termo leva a distorções e dificuldades de análise específica de cada problema na qual se pretende 
CLAUDIO, G. O.; SANTOS, L. B.

Os espaços da exclusão social na cidade de Campos dos Goytacazes - RJ

apresentar e buscar as devidas soluções. O primeiro ponto levantado pelo autor é que a exclusão não existe, porque determinado grupo ou indivíduo da sociedade está vinculado às formas produtivas, fazendo parte, portanto, de uma "inclusão precária e instável, marginal" (MARTINS, 1997, p. 26). Para ele, a exclusão levaria a um discurso equivocado e empobrecimento do termo.

[...] a palavra exclusão indica uma dificuldade, mas que uma certeza - revela uma incerteza no conhecimento que se pode ter a respeito daquilo que constitui o objeto da nossa preocupação - a preocupação com os pobres, os marginalizados, os excluídos os que estão procurando identidade e um lugar aceitável na sociedade. Portanto, a palavra exclusão nos fala, possivelmente, de um lado, da necessidade prática de uma compreensão nova daquilo que, não faz muito tempo, todos chamávamos de pobreza (MARTINS, 1997, p. 28).

O problema da exclusão estaria então no arquétipo e no tempo em que a sociedade leva para ser inserida em tais formas produtivas, pois "o tempo que o trabalhador passa a procurar trabalho começou a se tornar excessivamente longo e frequentemente o modo que se encontra para ser incluído, é um modo que implica certa degradação" (MARTINS, 1997, p. 32). Isso tem dificultado cada vez mais a inclusão da população que se encontra marginalizada, em situações precárias, a um padrão de vida que acompanhe o desenvolvimento econômico do país. E, o que era antes visto como um processo de transição de uma exclusão para uma inclusão, torna-se o próprio modo de vida dessa população, que, amiúde, não consegue visualizar, em seu meio, perspectiva de melhoria nas suas condições de vida.

Para Vieira (2009), embora a exclusão social esteja relacionada com o espaço, ela diz respeito às relações sociais que podem receber influência do espaço e também pode se territorializar. Ela também pode não ocorrer quando as pessoas e grupos não expressam vínculo com o lugar em que estão inseridas. Nessa perspectiva não há como pensar apenas em segregação socioespacial quando falamos da estrutura espacial urbana, pois estas contam com uma gama de relações sociais que não podem ser ignoradas. Ao abordarmos essa questão, vemos que este "não é um processo natural, mas é resultado inerente das contradições das relações sociais, das lutas de classe no modo de produção capitalista, refletidas e expressas na organização e estruturação do espaço intra-urbano" (VIEIRA, 2009, p. 60).

Assim como ressalta Martins (2002, p. 17), “o uso da definição de exclusão social para classificar as desigualdades sociais revela-nos um dos aspectos da crise da sociedade de classes”. Mas, precisamos ter em mente que a exclusão ou os excluídos não se caracterizam 
CLAUDIO, G. O.; SANTOS, L. B.

Os espaços da exclusão social na cidade de Campos dos Goytacazes - RJ

como classe social. As classes sociais, compostas principalmente por uma população trabalhadora, dependentes e pobres, podem fazer parte de uma mesma classe social, podem estar incluídas/excluídas de diferentes formas, podendo fazer parte de um modo de reprodução do capital, mas ao mesmo tempo não fazendo parte da mesma categoria de exclusão, que leva o indivíduo a não se identificar social e politicamente nas condições de exclusão. Como afirma Schwartzman (2004), o termo de exclusão nos permite trazer para o debate a "não efetivação da cidadania, ao fato de que, apesar da legislação social e do esforço das políticas sociais, uma grande massa de indivíduos não logra pertencer efetivamente a uma comunidade política e social" (SCHWARTZMAN, 2004, p.36).

\section{Indicadores socioeconômicos da cidade de Campos dos Goytacazes/RJ}

Partimos da análise demográfica da cidade com o intuito de compreender como ela tem se estruturado espacialmente. Campos teve um acréscimo populacional de $8 \%$ entre os anos de 1991 a 2010 e de $8 \%$ entre 2000 e 2010. Nos mesmos períodos, a população urbana aumentou $15 \%$ e $13 \%$, respectivamente, ao passo que a população rural encolheu $27 \%$ e $36 \%$, respectivamente (tabela 1$)$.

Tabela 1 - População total, por sexo e rural/urbana no município de Campos dos Goytacazes - RJ

\begin{tabular}{l|c|c|c|c|c|c}
\hline População & $\begin{array}{c}\text { População } \\
(\mathbf{1 9 9 1 )}\end{array}$ & $\begin{array}{c}\text { \% do Total } \\
(\mathbf{1 9 9 1})\end{array}$ & $\begin{array}{c}\text { População } \\
(\mathbf{2 0 0 0})\end{array}$ & $\begin{array}{c}\text { \% do Total } \\
(\mathbf{2 0 0 0})\end{array}$ & $\begin{array}{c}\text { População } \\
(\mathbf{2 0 1 0})\end{array}$ & $\begin{array}{c}\text { \% do Total } \\
(\mathbf{2 0 1 0})\end{array}$ \\
\hline Total & 376.496 & 100 & 407.118 & 100 & 463.731 & 100 \\
\hline Masculina & 183.660 & 48,78 & 196.779 & 48,33 & 223.259 & 48,14 \\
\hline Feminina & 192.836 & 51,22 & 210.339 & 51,67 & 240.472 & 51,86 \\
\hline Urbana & 317.981 & 84,46 & 364.177 & 89,45 & 418.725 & 90,29 \\
\hline Rural & 58.515 & 15,54 & 42.941 & 10,55 & 45.006 & 9,71 \\
\hline
\end{tabular}

Fonte: PNUD, Ipea e FJP, 2018.

Com isso, aumentou o grau de urbanização do município, que atingiu mais de 90\% da população residente no espaço urbano. Nos últimos três censos populacionais, notamos um pequeno aumento percentual da população feminina, que é a maioria, e diminuição do percentual da população masculina. Ao tratarmos a estrutura etária do município, (tabela 2), percebemos que, no período analisado, uma grande parcela da população $(68,75 \%)$ encontra-se na faixa 15 a 65 anos, seguida por $23 \%$ de jovens com menos de 15 anos. Grande parte da população se caracteriza como economicamente ativa, 
CLAUDIO, G. O.; SANTOS, L. B.

Os espaços da exclusão social na cidade de Campos dos Goytacazes - RJ

quer dizer, está inserida no mercado de trabalho ou à procura de alguma atividade remunerada. Assim como ocorre no padrão da pirâmide etária nacional, o município de Campos apresenta um crescimento populacional de jovens (a partir de 15 anos) e adultos e, consequentemente, um aumento absoluto e relativo da população idosa.

Tabela 2 - Estrutura Etária da População - Município - Campos dos Goytacazes - RJ

\begin{tabular}{l|c|c|c|c|c|c}
\hline \multicolumn{1}{c|}{ Estrutura Etária } & $\begin{array}{c}\text { População } \\
\mathbf{( 1 9 9 1 )}\end{array}$ & $\begin{array}{c}\text { \% do Total } \\
\mathbf{( 1 9 9 1 )}\end{array}$ & $\begin{array}{c}\text { População } \\
\mathbf{( 2 0 0 0 )}\end{array}$ & $\begin{array}{c}\text { \% do } \\
\text { Total } \\
(\mathbf{2 0 0 0})\end{array}$ & $\begin{array}{c}\text { População } \\
\mathbf{( 2 0 1 0 )}\end{array}$ & $\begin{array}{c}\text { \% do Total } \\
\mathbf{( 2 0 1 0 )}\end{array}$ \\
\hline Menos de 15 anos & 119.756 & 31,81 & 111.190 & 27,31 & 107.288 & 23,14 \\
\hline $\begin{array}{l}\text { 15 a 64 anos } \\
\text { População de 65 anos ou } \\
\text { mais }\end{array}$ & 236.391 & 62,79 & 267.994 & 65,83 & 318.833 & 68,75 \\
\hline Razão de dependência & 20.349 & 5,4 & 27.934 & 6,86 & 37.610 & 8,11 \\
\hline Taxa de envelhecimento & 5,4 & - & 6,86 & - & 8,11 & - \\
\hline
\end{tabular}

Fonte: PNUD, Ipea e FJP, 2018

Porém, o que chama atenção, entre os anos 1991 e 2010, é a razão de dependência que vai de 59,27 da população em 1991 para 45,45 em 2010, ou seja, temos um quadro em que, apesar do processo de aumento na taxa de envelhecimento, a parcela mais idosa encontra-se ativa economicamente. Segundo dados do Altas Brasil (2018), houve diminuição na taxa de atividade da população acima de 18 anos, que corresponde à parcela da população economicamente ativa, passando de 62,34\%, em 2000, para 61,38\%, em 2010. Contudo, tivemos a diminuição daqueles que se encontravam economicamente ativos e desocupados (de 14,59\%, em 2000, para 10,19\% em 2010), acarretando uma concorrência cada vez maior no mercado de trabalho.

O Índice de Desenvolvimento Humano, ajustado à realidade dos municípios IDHM, elaborado pelo Programa das Nações Unidas para o Desenvolvimento (PNUD), foi criado para fazer a quantificação do desenvolvimento da população municipal. O índice envolve as dimensões de três indicadores: educação, renda e longevidade. A mensuração desses indicadores visa avaliar as condições de se ter "oportunidade de viver uma vida longa e saudável, de ter acesso ao conhecimento e ter um padrão de vida que garanta as necessidades básicas, representadas pela saúde, educação e renda" (PNUD, 2018).

Além de seguir os mesmos padrões de IDH global, o IDHM é adequado à realidade brasileira, seguindo, assim, a disponibilidade dos indicadores. E são utilizados para analisar o desenvolvimento dos municípios, num agrupamento por média geométrica, numa 
CLAUDIO, G. O.; SANTOS, L. B.

Os espaços da exclusão social na cidade de Campos dos Goytacazes - RJ

variação que vai de 0 a 1: Muito Alto, de 0,800 a 1,000; Alto, de 0,700 a 0,799; Médio, de 0,600 a 0,699; Baixo, de 0,500 a 0,599; Muito baixo, de 0,000 a 0,499. A importância do IDHM, em escala menor que o IDH, possibilita analisarmos com mais precisão as questões sociais e econômicas nos municípios.

O Estado do Rio de Janeiro, com 0,727, possui a quarta posição no ranking de IDHM por estados. O município de Campos dos Goytacazes ocupa a posição1427 a entre os 5.565 municípios brasileiros. O índice do município apresentou incremento de 0,505, em 1991, para 0,618, em 2000, e 0,716, em 2010, estando dentro da faixa alta de IDHM (PNUD, 2018). Analisaremos, a seguir, os componentes que contribuem para tal classificação (tabela 3). O componente de longevidade foi o que mais colaborou com o $\operatorname{IDHM}(0,83)$, seguido por renda $(0,715)$ e educação $(0,619)$. Nas últimas décadas, o componente de educação foi o que mais colaborou para o crescimento do IDHM, pois dobrou sua participação percentual. A inserção de crianças entre 5 e 6 anos na escola é o índice com maior avanço percentual.

Tabela 3 - Índice de Desenvolvimento Humano Municipal de Campos dos Goytacazes - RJ

\begin{tabular}{|c|c|c|c|}
\hline IDHM e componentes & 1991 & 2000 & 2010 \\
\hline IDHM Educação & 0,318 & 0,474 & 0,619 \\
\hline$\%$ de 18 anos ou mais com fundamental completo & 33,55 & 41,76 & 55,5 \\
\hline$\%$ de 5 a 6 anos na escola & 51,03 & 87,83 & 95,78 \\
\hline $\begin{array}{l}\text { \% de } 11 \text { a } 13 \text { anos nos anos finais do fundamental Regular Seriado ou } \\
\text { com fundamental completo }\end{array}$ & 35,91 & 55,39 & 77,3 \\
\hline$\%$ de 15 a 17 anos com fundamental completo & 22,6 & 35,7 & 49,24 \\
\hline$\%$ de 18 a 20 anos com médio completo & 14,12 & 22,53 & 39,31 \\
\hline IDHM Longevidade & 0,658 & 0,751 & 0,83 \\
\hline Esperança de vida ao nascer & 64,45 & 70,06 & 74,82 \\
\hline IDHM Renda & 0,617 & 0,662 & 0,715 \\
\hline Renda per capita & 371,75 & 490,87 & 682,59 \\
\hline
\end{tabular}

Fonte: PNUD, Ipea e FJP, 2018

O componente de educação traz informações sobre aqueles que frequentam ou que já completaram algum ciclo escolar. Segundo dados do Atlas Brasil (2018), entre anos de 1991 e 2010, houve um aumento percentual de 44,75\% de crianças de 5 a 6 anos em idade escolar; 41,39\% de crianças de 11 a 13 anos com o ensino fundamental; 26,64\% de jovens de 15 a 17 com o ensino fundamental completo e $25,19 \%$ de jovens de 18 a 20 anos com ensino médio.

Contudo, apesar dos avanços, os indicadores de educação mostram que o município apresentou percentual significativo de jovens com ensino fundamental e médio incompletos, componente que reflete na qualificação profissional e na inserção no mercado de Revista Cerrados, Montes Claros/MG, v.17, n. 2, p. 66-95, jul./dez.-2019. 
CLAUDIO, G. O.; SANTOS, L. B.

Os espaços da exclusão social na cidade de Campos dos Goytacazes - RJ

trabalho. $\mathrm{O}$ número daqueles que ingressam nas escolas é menor quando comparado àqueles que concluem o ensino fundamental no tempo previsto, remetendo-nos a pensar numa educação para além do quantitativo, de modo a visualizar a dimensão qualitativa, na qual os reflexos vão surgir ao longo dos anos, não apenas na educação, mas em todo desenvolvimento do indivíduo, seja ele inserido no mercado de trabalho, seja exercendo sua condição de cidadão.

Como vimos anteriormente, o indicador de longevidade é um dos principais responsáveis pelo crescimento do IDHM de Campos dos Goytacazes. Trata-se de um indicador que tem a ver com a esperança de vida ao nascer e com as demais taxas de mortalidade e fecundidade, refletindo nas condições de saúde da população (tabela 4).

Tabela 4 - Longevidade, mortalidade e fecundidade no município de Campos dos Goytacazes/RJ

\begin{tabular}{l|c|c|c}
\hline & $\mathbf{1 9 9 1}$ & $\mathbf{2 0 0 0}$ & $\mathbf{2 0 1 0}$ \\
\hline Esperança de vida ao nascer & 64,5 & 70,1 & 74,8 \\
\hline Mortalidade infantil & 36,1 & 18,2 & 14,7 \\
\hline Mortalidade até 5 anos de idade & 41,3 & 20,6 & 16,6 \\
\hline Taxa de fecundidade total & 2,4 & 2,2 & 2,1 \\
\hline
\end{tabular}

Fonte: PNUD, Ipea e FJP, 2018

Percebemos que houve um aumento de 10 anos de esperança de vida ao nascer, saltando de 64,5 para 74,8 anos, entre 1991 e 2010. A mortalidade infantil, que é a razão entre o número de mortes de crianças com menos de um ano por mil nascidos vivos, mostrou uma queda de superior a 50\%, ao passo que a mortalidade de até 5 anos de idade reduziu mais de 60\%. No mesmo período, caiu a taxa de fecundidade. Considerando a classificação do Datasus (Departamento de Informática do SUS), - taxas de mortalidade infantil são geralmente classificadas em altas (50 ou mais), médias (20-49) e baixas (menos de 20) -, podemos afirmar que a taxa de mortalidade em Campos dos Goytacazes é considerada baixa, acompanhando as tendências mostradas em países desenvolvidos. Essa melhoria do indicador tem a ver com as políticas de pré-natal, parto e proteção da saúde infantil que foram implementadas.

Quanto à renda, terceiro componente do IDHM, entre os anos de 1991 e 2010, tivemos redução de $12 \%$ da população que se encontrava em situação de extrema pobreza (tabela 5). 
CLAUDIO, G. O.; SANTOS, L. B.

Os espaços da exclusão social na cidade de Campos dos Goytacazes - RJ

Tabela 5 - Renda, pobreza e desigualdade no município de Campos dos Goytacazes-RJ

\begin{tabular}{l|c|c|c}
\hline Indicadores/período & $\mathbf{1 9 9 1}$ & $\mathbf{2 0 0 0}$ & $\mathbf{2 0 1 0}$ \\
\hline Renda per capita & 371,75 & 490,87 & 682,59 \\
\hline$\%$ de extremamente pobres & 15,66 & 6,47 & 3,67 \\
\hline$\%$ de pobres & 42,13 & 23,75 & 13,49 \\
\hline Índice de Gini & 0,62 & 0,56 & 0,55 \\
\hline
\end{tabular}

Fonte: PNUD, Ipea e FJP, 2018

Houve, ainda, a diminuição de 28,54\% de pobres entre 1991 a 2010, sendo $10,26 \%$ entre 2000 e 2010 de pobres que vivem em domicílios particulares permanentes com renda domiciliar per capita igual ou inferior a R \$ 140. Em 2010, a renda per capita era de R\$ 682,59, mostrando que, apesar da queda do percentual de pobreza, temos um número significativo daqueles que recebem menos que o valor da renda per capita.

O componente de renda faz uso de índice de Gini para medir a pobreza. Para Villaça $(2012)^{2}$ é o principal meio de assimilar os processos de segregação e analisar a pobreza. Segundo informações do IPEA, o Índice de Gini é um instrumento para medir o grau de concentração de renda em determinado grupo, "é uma medida menos intuitiva, porém mais abrangente da evolução da desigualdade" (IPEA, 2012). Ele "herda no seu cálculo os pesos da função bem-estar" e tal função nada mais é do que o PIB per capita que agrega num único número o "bem-estar individual" ao bem-estar social sem considerar as desigualdades, é apenas a soma de riquezas produzidas.

O índice de Gini é capaz de apontar a diferença entre os rendimentos, comparando os $20 \%$ mais pobres com os $20 \%$ mais ricos, podendo variar "de 0 a 1: no seu mínimo todos são iguais, e no seu ápice uma pessoa detém todos os recursos da economia" (IPEA, 2012, p. 3). Quanto mais próximo de zero, maior igualdade absoluta e equidade de renda, ao passo que, quanto mais próximo de um, maior a concentração de riqueza e maior é a desigualdade.

É importante lembrar que a desigualdade de riqueza é diferente da desigualdade de salário, porque a população rica não vive de salário, o que não reflete a desigualdade de riqueza. O Brasil vinha apresentando, desde a década de 1960, uma diminuição do nível de desigualdade. Contudo, vale ressaltar que, ao analisarmos o contexto mundial, o país ainda se encontra num quadro de desigualdade.

O Brasil atingiu em 2011, pela PNAD, seu menor nível de desigualdade de renda desde os registros nacionais iniciados em 1960. Na verdade, a desigualdade no

2 Vídeo Palestra de PGAU CIDADE - UFSC - Flávio Villaça - Desigualdade Socioeconômica no Brasil. Disponível em: https://www.youtube.com/watch?v=Z-zIP73X40Y

Revista Cerrados, Montes Claros/MG, v.17, n. 2, p. 66-95, jul./dez.-2019. 
CLAUDIO, G. O.; SANTOS, L. B.

Os espaços da exclusão social na cidade de Campos dos Goytacazes - RJ

Brasil permanece entre as 15 maiores do mundo, e levaria pelo menos 20 anos no atual ritmo de crescimento para atingir níveis dos Estados Unidos, que não são uma sociedade igualitária. Porém, isso significa que existem consideráveis reservas de crescimento pró-pobre, que só começaram a ser exploradas na década passada (IPEA, 2012, p. 8).

Situação parecida é verificada na cidade de Campos dos Goytacazes, em que o índice de Gini tem diminuído, passando de 0,62, em 1991, para 0,56, em 2000, e para 0,55, em 2010. Contudo, vale ressaltar, como destaca Villaça (2012), que a redução da pobreza não significa que a desigualdade tenha diminuído, pois, se temos a redução da pobreza e o aumento da riqueza, a desigualdade em si ainda se apresenta de forma significativa. A desigualdade de riqueza apresentada pelo índice de Gini, apesar de exibir uma diminuição, não se apresenta de forma acentuada.

\footnotetext{
Sem essa redução da desigualdade, a renda média precisaria ter aumentado quase $89 \%$ entre 2001 e 2011 para que a pobreza tivesse a mesma queda. Mesmo com todo o crescimento dos anos 2000 até agora, no entanto, o aumento efetivamente registrado no período foi de apenas $32 \%$. Ou seja, o crescimento econômico teria de ter sido mais do que duas vezes maior do que o registrado, o que parece muito pouco factível. Na prática, isso significa que, a não ser que o Brasil consiga registrar taxas chinesas de crescimento econômico, nos próximos anos o combate à pobreza dependerá muito mais da redução da desigualdade do que de aumentos da renda média (IPEA, 2012, p. 33).
}

A redução da desigualdade em Campos nos anos 2000 pode ser explicada por fatores como rendimentos de trabalho, que contribuíram com 58\% da queda do índice de Gini, e transferências sociais, como a previdência social e o bolsa família, que colaboraram com $32 \%$ para a diminuição. Porém, apesar de sua redução, a desigualdade ainda se faz presente nas grandes cidades e também em cidades médias brasileiras, podendo ser medidas e analisadas por meio de indicadores de exclusão social.

\section{Exclusão social na escala intraurbana de Campos dos Goytacazes}

A escolha pela análise da exclusão social na escala intraurbana decorre da necessidade de se olhar para onde ocorre toda dinâmica social e econômica. É a escala onde os processos de exclusão social são mais evidentes. Entendemos que, ao adentrarmos na menor escala de coleta de dados que o IBGE disponibiliza, que é formada pelos setores censitários, podemos encontrar onde estão espacializadas as dimensões dos processos de 
CLAUDIO, G. O.; SANTOS, L. B.

Os espaços da exclusão social na cidade de Campos dos Goytacazes - RJ

exclusão social. Nossa análise recai sobre a malha urbana do distrito de Campos dos Goytacazes, composta por 78 bairros (mapa 2).

Mapa 2 - Bairros da cidade de Campos dos Goytacazes-RJ

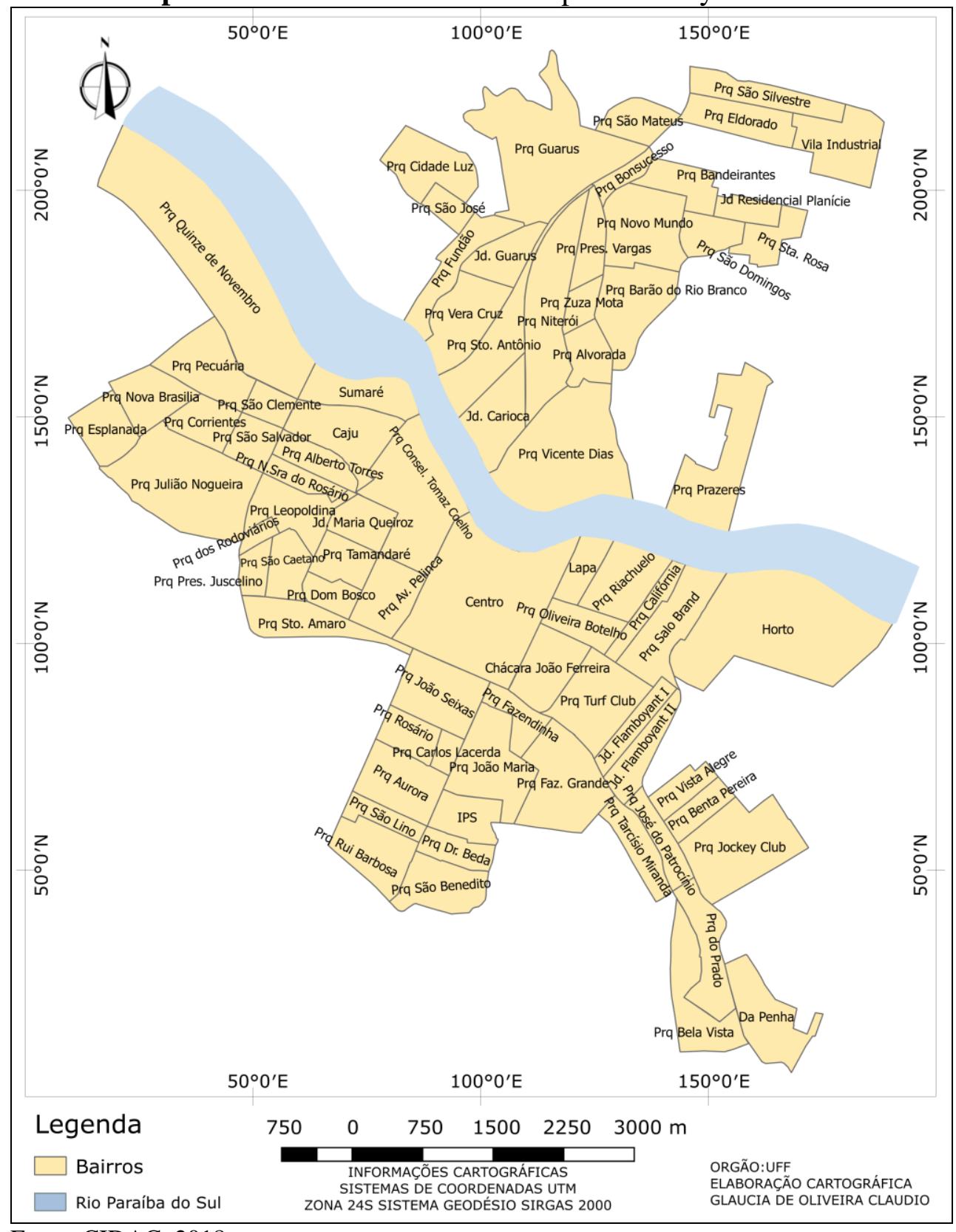

Fonte: CIDAC, 2018

Por meio dos quatro indicadores (demografia, economia, ambiente e educação), selecionamos as principais variáveis (tabela 6) para realizar a espacialização da exclusão social na cidade de Campos dos Goytacazes.

Revista Cerrados, Montes Claros/MG, v.17, n. 2, p. 66-95, jul./dez.-2019. 
CLAUDIO, G. O.; SANTOS, L. B.

Os espaços da exclusão social na cidade de Campos dos Goytacazes - RJ

Tabela 6 - Indicadores e variáveis selecionados

\begin{tabular}{c|c|c|c|c}
\hline Indicadores & Educação & Ambiente & Economia & Demografia \\
\hline & \% alfabetizados & $\%$ domicílios ligados à & $\%$ responsáveis de até & \\
& de 10 a 14 anos & rede de esgoto & dois salários mínimos, & Média de moradores \\
Variáveis & $\%$ responsáveis & $\%$ domicílios sem acesso & $\%$ responsáveis de até & por domicílio com até \\
& alfabetizados & a banheiro & vinte salários mínimos & aproximadamente \\
& & $\%$ domicílios com quatro & $\%$ responsáveis sem & cinco moradores \\
& & ou mais banheiros & rendimento & \\
\hline
\end{tabular}

Fonte: Martinuci (2016).

Por conta da grande concentração populacional em alguns bairros e da utilização de coleta de dados por setor censitário, alguns bairros exibem quatro ou mais setores censitários. Quando analisamos a expansão urbana de Campos e da formação da sua periferia, notamos um processo permanente que promove a separação de uma classe formada por uma elite, que se instala próxima ao centro principal da cidade, e uma classe menos favorecida que, por conta das heranças históricas advindas de processos como a falência das usinas e da dificuldade de se inserir na área central, foi impelida a se instalar em áreas mais periféricas.

A fim de identificar os espaços marcados pela exclusão social, iniciamos com o indicador de demografia, que traz a variável de média de moradores por domicílio (mapa 3). No ano 2000, notamos que os setores com média de até cinco moradores por domicílio estão situados, principalmente, no eixo norte, na margem esquerda do rio Paraíba do Sul, um padrão que se intensificou no Censo de 2010.

Mapa 3 - Média de moradores por domicílio, por setor censitário, na cidade de Campos dos Goytacazes

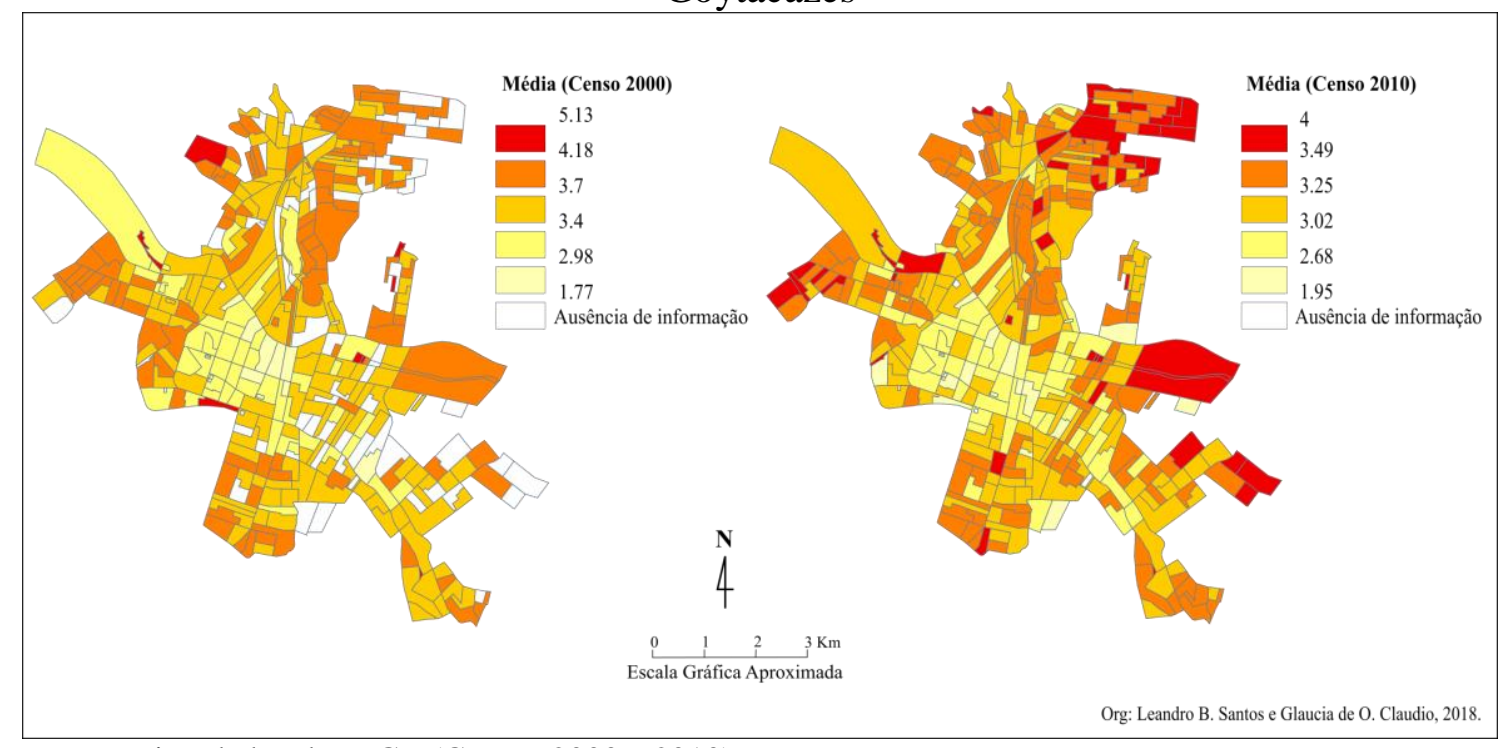

Fonte: Microdados do IBGE (Censos 2000 e 2010)

Revista Cerrados, Montes Claros/MG, v.17, n. 2, p. 66-95, jul./dez.-2019. 
CLAUDIO, G. O.; SANTOS, L. B.

Os espaços da exclusão social na cidade de Campos dos Goytacazes - RJ

Os setores com ausência de informação em 2000 aparecem, em 2010, com média de moradores de 3 a 4 por domicílio. Há certo destaque para o eixo norte da cidade, especificamente o subdistrito de Guarus que, no ano de 2010, é caracterizado por núcleos familiares numerosos. Trata-se, portanto, de uma área marcada por forte adensamento populacional e, com a criação de novos setores censitários, o adensamento elevado por domicílio se reafirma. Esse processo é intensificado principalmente onde estão localizados os bairros Parque São Silvestre, Parque Eldorado, Vila Industrial, Parque Santa Rosa, situados próximos ao limite urbano, nos sentidos norte e noroeste da cidade.

Outro ponto que podemos identificar é a intensificação dessa variável concentração de pessoas por domicílio no sentido a montante do Rio Paraíba do Sul, onde se localizam os bairros Parque Quinze de Novembro, Parque Nova Brasília e Parque Esplanada, que, assim como nos bairros citados anteriormente, encontram-se nos limites na malha urbana da cidade. Assim como na extremidade sudeste, o mesmo padrão se apresenta nos bairros da Penha, Parque do Prado e Parque Bela Vista, situados no sentido do distrito de Goytacazes.

Em contrapartida, percebemos a diminuição da concentração de pessoas por domicílio nos setores censitários situados próximos à área central da cidade, dispostos em bairros mais nobres, tais como Parque Av. Pelinca, Parque Dom Bosco, Parque Sto. Amaro e Parque Tamandaré. Vale destacar que a média de moradores por domicílio no centro da cidade, bem como nos bairros situados nas áreas nobres da cidade, varia entre 2 a 3 pessoas, enquanto as demais áreas citadas acima variam na média de 3 a 4 pessoas por domicílio.

Ao adentrarmos para a escala dos setores censitários, percebemos que, dentro de alguns bairros, as variáveis não ocorrem de forma homogênea. Os bairros onde estas divergências são apresentadas são Parque Guarus, Parque Cidade Luz, Parque Prazeres, Parque Vicente Dias, Parque Riachuelo e Horto. Dos seis bairros, quatro estão situados ao norte. O que vemos é que o contingente populacional da cidade de Campos não segue o padrão apresentado pela área central, principalmente no extremo norte da cidade. Essa porção da cidade apresentava, no ano de 2000, uma média de até 5 moradores por domicílio e, no ano de 2010, tal média ainda permanecia elevada.

No indicador de economia (mapa 4), utilizamos variáveis que examinam a distribuição salarial, tendo como base o salário mínimo. 
CLAUDIO, G. O.; SANTOS, L. B.

Os espaços da exclusão social na cidade de Campos dos Goytacazes - RJ

Mapa 4 - Responsáveis com até 2 SM, por setor censitário, na cidade de Campos dos Goytacazes

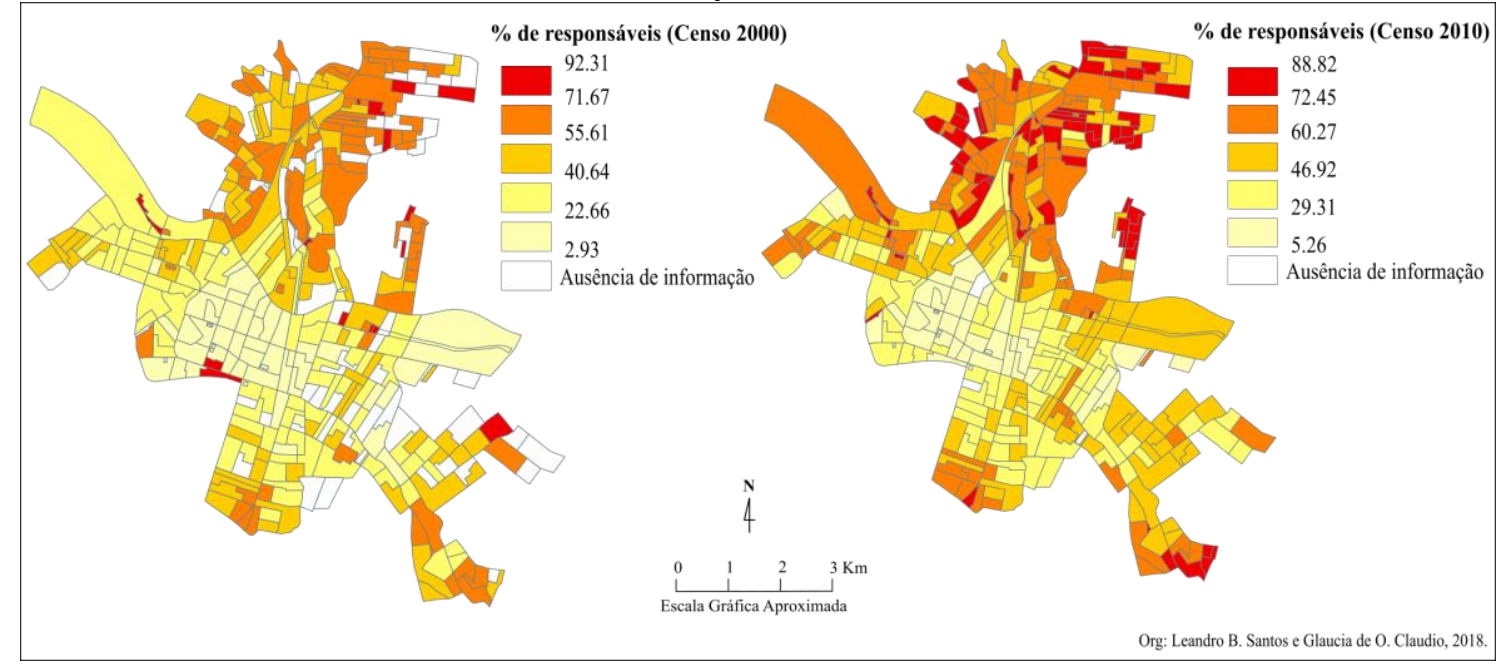

Fonte: Microdados do IBGE (Censos 2000 e 2010)

No ano de 2000, o salário mínimo era de $\mathrm{R} \$ 151,00$ reais $^{3}$, enquanto no ano de 2010 o salário mínimo era de $\mathrm{R} \$ 510,00$ reais ${ }^{4}$. A variável de responsáveis com até 2 salários mínimos mostra que, no ano de 2000, havia presença de oito setores com aproximadamente 92\% de responsáveis com rendimento nesta situação ao norte da cidade, em comparação com o eixo sul, com sete setores. Vale ressaltar a falta de informação de setores, ao norte da cidade, no Censo de 2000. No ano 2010, esses mesmos setores censitários apresentaram, de maneira expressiva, percentual entre $60 \%$ e $88 \%$ aproximadamente de responsáveis com até dois salários mínimos, reforçando a tendência de concentração de pessoas com baixo rendimento.

São nestes espaços situados ao norte onde estão parte relevante da população economicamente ativa da cidade. Quando analisado juntamente com o indicador anteriormente apresentado, percebemos que estes espaços são compostos por famílias de baixa renda, levando em consideração os grupos familiares numerosos. Quanto aos bairros que apresentam discrepância de setores correspondentes à variável de responsáveis com até dois salários mínimos, temos Parque Guarus, Parque Cidade Luz, Parque Prazeres, Parque Novo Mundo, Parque São Domingos e Penha.

Outro indicador importante corresponde aos responsáveis com mais de 20 salários mínimos (mapa 5), ou seja, aqueles que recebiam mais de 3 mil reais por mês no ano de 2000

\footnotetext{
${ }^{3}$ MP 2019 de 23/03/00 e 2019-1 de 20/04/00 Convertidas na Lei $n^{\circ}$ 9971, de 18/05/2000.

${ }^{4}$ Lei no 12.255 ,de 15.06 .2010
} 
CLAUDIO, G. O.; SANTOS, L. B.

Os espaços da exclusão social na cidade de Campos dos Goytacazes - RJ

e mais de 10 mil reais por mês no ano de 2010. É importante analisar esse indicador, porque ele permite que a melhor compreensão de onde estão aqueles que recebem mais de 20 salários mínimos, mostrando concentração numa pequena parcela da cidade, principalmente ao redor do eixo central.

Mapa 5 - Responsáveis com mais de 20 SM, por setor censitário, na cidade de Campos dos Goytacazes

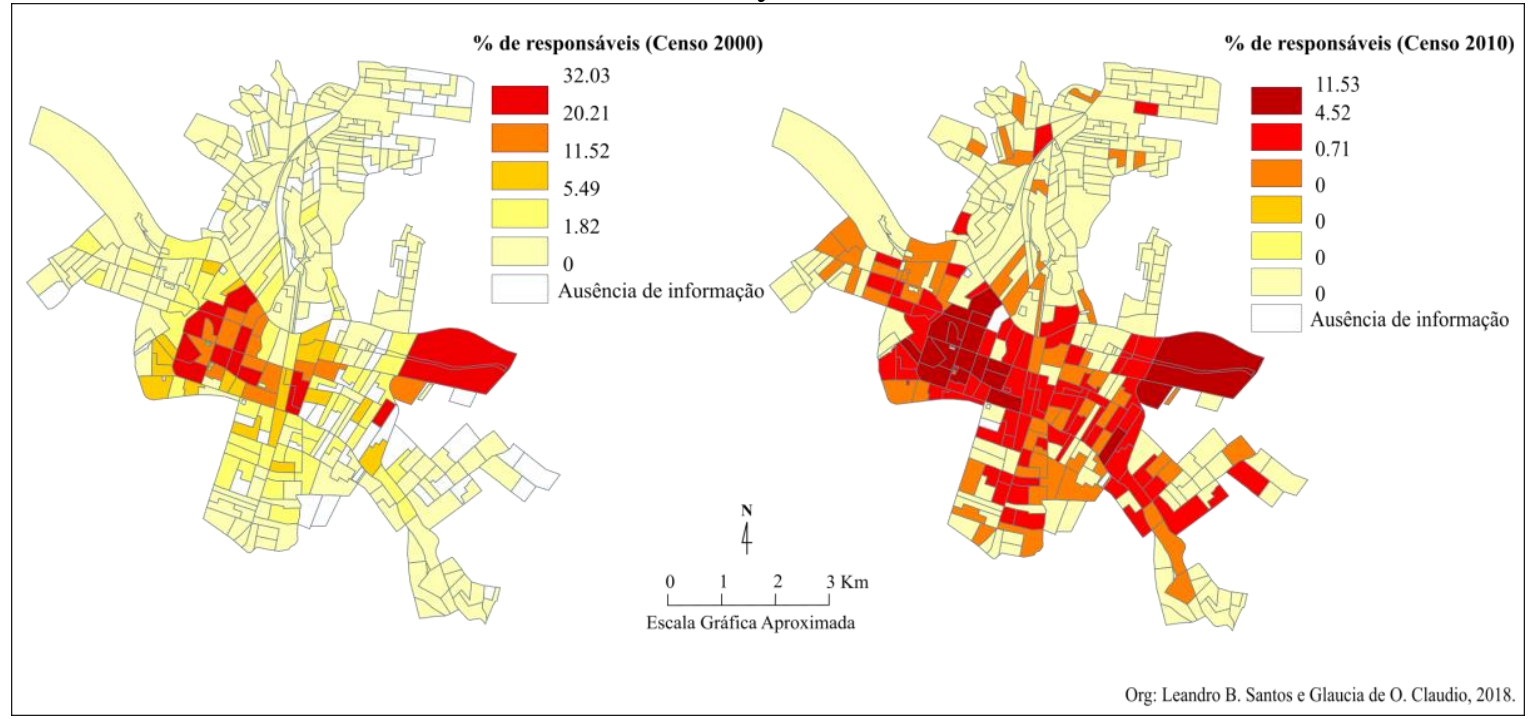

Fonte: Microdados do IBGE (Censos 2000 e 2010)

A análise isolada permite notar a concentração no eixo central da cidade no ano de 2000. Quando comparamos com o indicador de demografia, vemos que são as mesmas áreas onde a média de moradores por domicílio varia de 1 a 3 pessoas, no máximo. Sendo assim, os setores que apresentam domicílios com baixa média de moradores são os mesmos que exibem o percentual entre $11 \%$ a $32 \%$ de responsáveis que recebem mais de 3 mil reais. Enquanto isso, as demais áreas, com o percentual de até $5 \%$ de responsáveis, não podem ser caracterizadas como sendo compostas de uma elite econômica, levando em consideração que são setores censitários em que as pessoas residentes variam de 3 a 4 moradores por domicílio no ano de 2000.

A mudança significativa que ocorre ao fazermos a comparação dos censos de 2000 e de 2010 se dá em função do papel desempenhado pela exploração de petróleo na Bacia de Campos na economia da cidade. A intensificação da exploração de petróleo contribuiu para alavancar, direta e indiretamente, o mercado de trabalho, inserindo muitos chefes de família nessa dinâmica. Além disso, Campos dos Goytacazes também passa a ser polo universitário e 
CLAUDIO, G. O.; SANTOS, L. B.

Os espaços da exclusão social na cidade de Campos dos Goytacazes - RJ

centro de serviços de saúde com grande relevância regional. Estas duas atividades, somadas à dinâmica do comércio e dos serviços, contribuíram para atrair mão de obra especializada oriundas de outras cidades.

Vemos que, apesar do crescimento de outras áreas, o padrão do ano de 2000 se apresenta da mesma maneira no ano de 2010, marcando as mesmas áreas com elevado percentual de responsáveis com mais de 20 salários mínimos. A diferença é que este padrão se tornou ainda mais concentrado no ano de 2010, tendo em vista que apenas aproximadamente 12\% dos chefes de família recebiam mais de 20 salários mínimos por mês. O que ocorreu, de fato, foi uma maior concentração da renda.

Podemos notar, também, que no eixo norte aparecem alguns setores de forma isolada com percentuais que variam de $0,7 \%$ a 4,5\%. Isso traz, mais uma vez, a questão da discrepância dos setores censitários dentro de alguns bairros da cidade. Novamente, destacamse o Parque Guarus, o Parque Eldorado, o Parque Fundão e o Parque Vicente Dias. Vale lembrar que tal situação não caracteriza estes bairros na sua totalidade, trata-se apenas de casos isolados que não vão ao encontro da realidade da maioria dos chefes de família que estão situadas nestes bairros.

Outra variável do de indicador de economia é a responsáveis por domicílio sem rendimento (mapa 6). A variável mostra responsáveis por domicílios que não estão inseridos no mercado de trabalho formal e que sequer logram renda no mercado informal.

Mapa 6 - Responsáveis sem rendimento, por setor censitário, na cidade de Campos dos Goytacazes

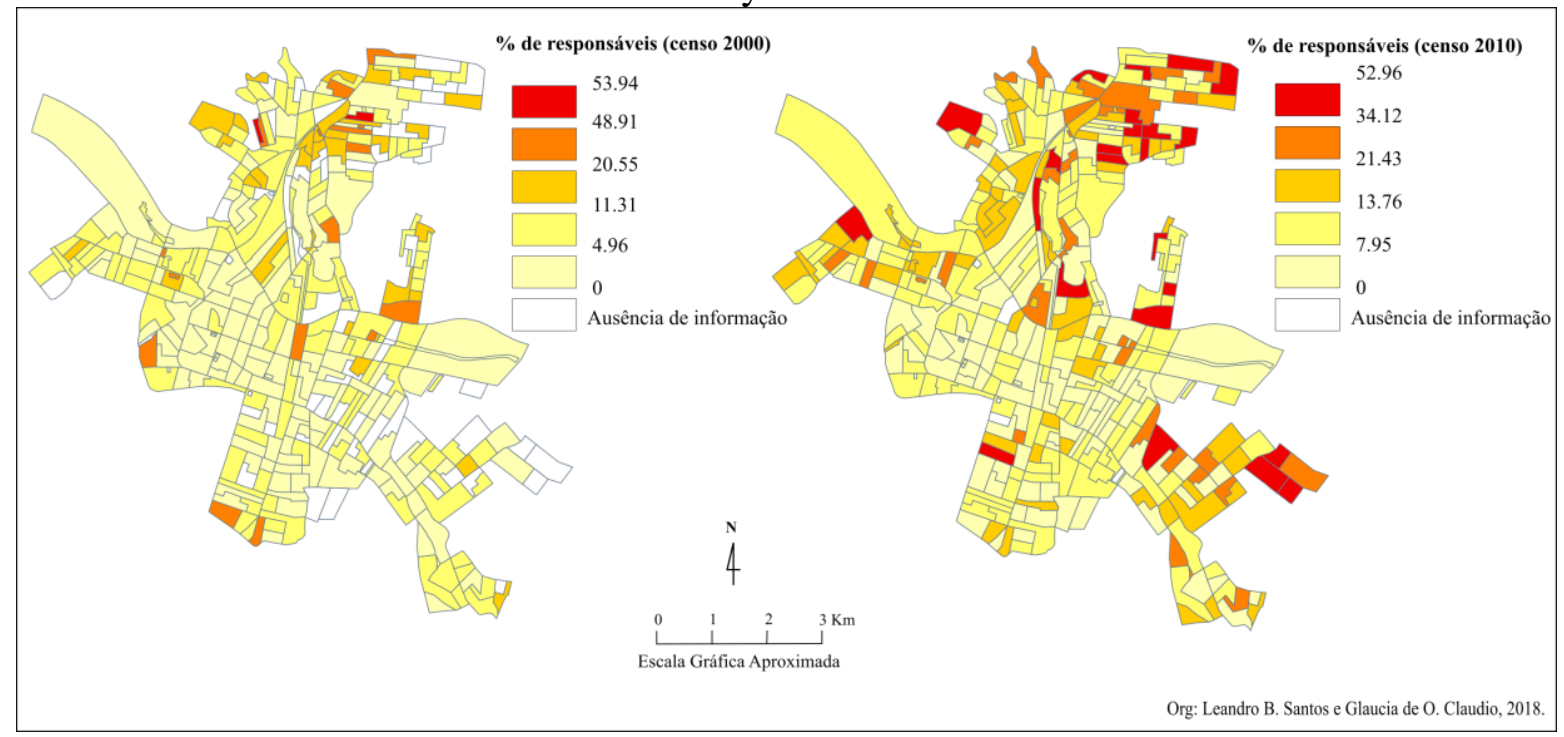

Fonte: Microdados do IBGE (Censos 2000 e 2010)

Revista Cerrados, Montes Claros/MG, v.17, n. 2, p. 66-95, jul./dez.-2019. 
CLAUDIO, G. O.; SANTOS, L. B.

Os espaços da exclusão social na cidade de Campos dos Goytacazes - RJ

Novamente, no ano de 2000, o eixo norte se destacou quanto a esse indicador, por apresentar setores que variaram entre $11 \%$ a $53 \%$ de responsáveis sem rendimento, principalmente Parque Guarus e Parque Bandeirante, nos quais havia setores com percentuais próximos de 53\%. E, no ano de 2010, destacam-se os bairros de Parque Prazeres, Parque Industrial, Parque São Silvestre, Parque São Mateus, Parque Santa Rosa e Parque Cidade Luz, situados à margem esquerda do rio. Na margem direita do Rio Paraíba do Sul, temos os bairros Parque Pecuária e Parque Rosário. São os bairros que, apesar de não apresentarem setores com 53\% de responsáveis sem rendimento no ano de 2000, aparecem no ano de 2010.

Portanto, o uso das variáveis do indicador de economia é importante na identificação de um dos principais processos de exclusão social, o desemprego. Isso nos mostra que, apesar do importante papel econômico e dinamismo que Campos assumiu nas últimas três décadas, por conta da expansão das atividades relacionadas à exploração de petróleo e de atividades econômicas de comércio e serviços, a distribuição da riqueza no espaço intraurbano foi extremamente desigual. O que se apresenta na escala intraurbana é a desigualdade de salários, que são baixos ou inexistentes para parcela relevante da população.

No indicador de ambiente, a variável de domicílios ligados à rede de esgoto (mapa 7) mostra quais são as localidades têm acesso a um serviço básico e crucial para a cidadania.

Mapa 7 - Domicílios com acesso à rede de esgoto (\%), por setor censitário, na cidade de Campos dos Goytacazes

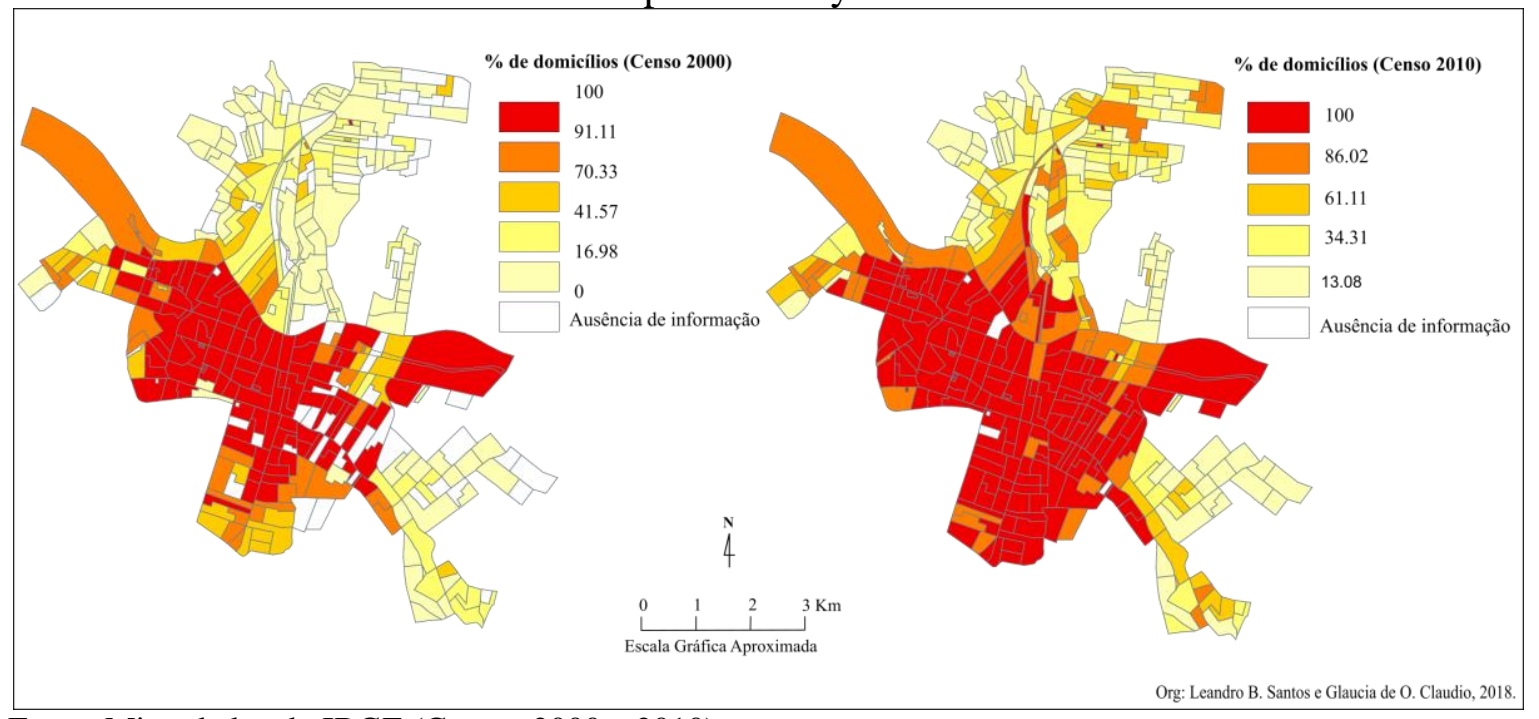

Fonte: Microdados do IBGE (Censos 2000 e 2010)

No ano 2000, constatamos certa concentração do serviço de acesso à rede de esgoto na margem direita do Rio Paraíba do Sul, em que grande parte dos setores próximos à Revista Cerrados, Montes Claros/MG, v.17, n. 2, p. 66-95, jul./dez.-2019. 
área central exibe de $90 \%$ a 100\% de acesso. Na margem esquerda, a falta de acesso à rede de esgoto apresenta deficiência em boa parte dos setores. O que chama atenção é que esta falta de acesso não é visível apenas nos limites da malha urbana, na qual poderíamos entender como sendo áreas em expansão. O que temos notado é a falta ou o baixo acesso a rede de esgoto, que está presente em $41 \%$ dos domicílios, em todo eixo norte no ano de 2000.

No ano de 2010, houve um aumento de acesso à rede de esgoto no eixo norte, mas a falta de acesso ainda se mostrou significativa nos bairros Parque Prazeres, Parque Guarus, Parque Cidade Luz, Parque São Silvestre, Parque Eldorado e Vila Industrial, cujos setores censitários atingem, no máximo, de $86 \%$ de domicílios com acesso. Podemos destacar o bairro de Parque Prazeres que, apesar de sua proximidade física com o eixo central da cidade, apresenta apenas um setor com 34\%, enquanto os demais não possuem acesso à rede, assim como também o bairro de Parque Cidade Luz, onde todos os setores exibem falta de acesso, com efeitos na saúde da população.

A variável domicílios sem acesso a banheiro ajuda a identificar onde estão os domicílios que se encontram em situações precárias (mapa 8). Essa variável varia de 4\% a $53 \%$ no ano de 2000, estando presente nos mesmos setores que mostram ausência de acesso à rede de esgoto. No ano de 2010, apesar da diminuição de 58\% de domicílios sem acesso a banheiro, essa variável se apresenta de forma significativa, considerando que é prevalente em setores com média de 3 a 4 moradores e de baixa renda.

Mapa 8 - Domicílios sem banheiro (\%), por setor censitário, na cidade de Campos dos Goytacazes

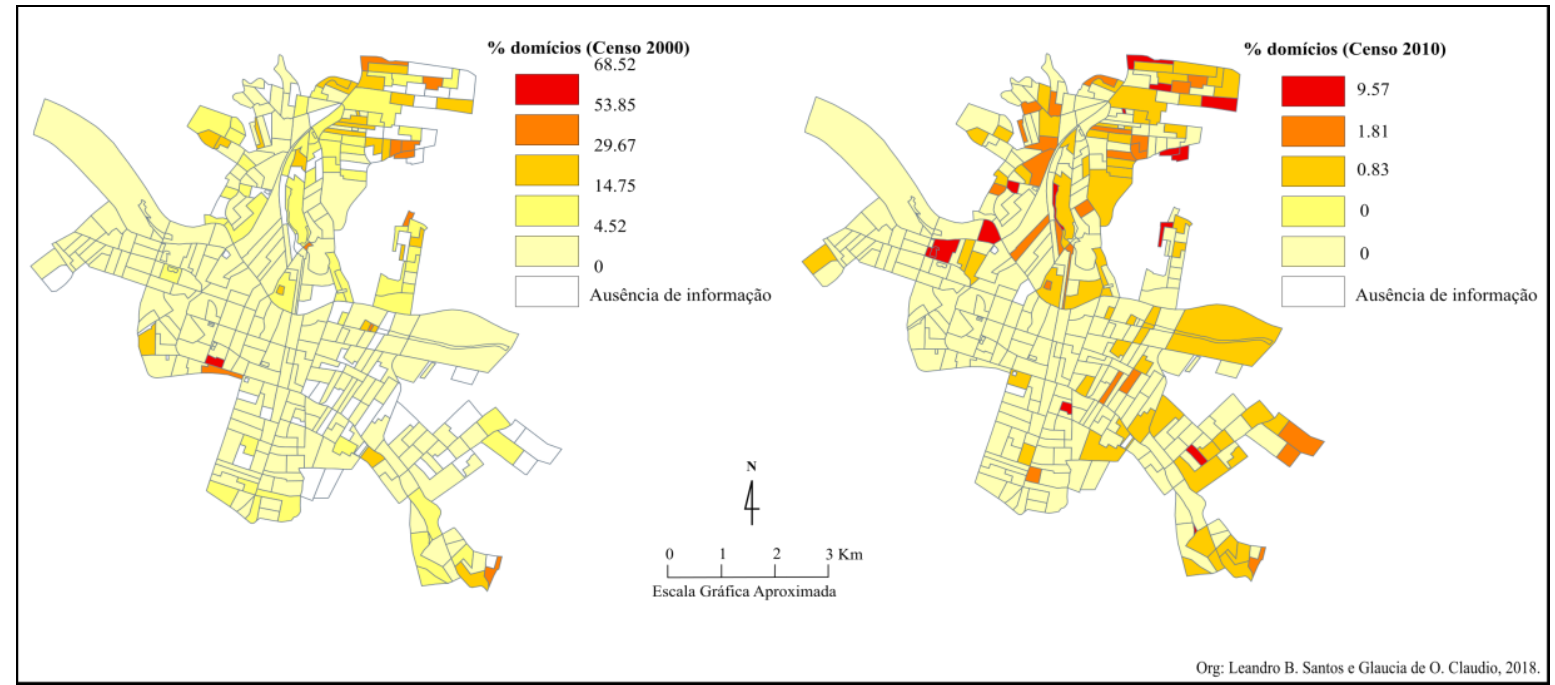

Fonte: Microdados do IBGE (Censos 2000 e 2010)

Revista Cerrados, Montes Claros/MG, v.17, n. 2, p. 66-95, jul./dez.-2019. 
CLAUDIO, G. O.; SANTOS, L. B.

Os espaços da exclusão social na cidade de Campos dos Goytacazes - RJ

Com a tardia atenção dada ao eixo norte da malha urbana da cidade em planos urbanísticos nos anos 1940, esta porção encontrou-se excluída de projetos urbanísticos com acesso à rede de esgoto. Este processo de exclusão aparece na cidade no censo de 2000 e, mesmo havendo o aumento percentual no ano de 2010, chama atenção o fato que o eixo norte ainda apresenta setores censitários com percentuais que variam de $14 \%$ a $66 \%$ de domicílios sem ligação à rede de esgoto. Os setores com baixo acesso à rede de esgoto se sobrepõem àqueles com domicílios com maior número de pessoas e menor poder aquisitivo.

Para compreender a exclusão através deste indicador de ambiente, precisamos entender que aqueles que estão excluídos desse acesso, ou seja, aqueles que não recebem do poder público a totalidade de um serviço básico, estão na vertente oposta daqueles que concentram o acesso ao serviço de saneamento básico e vivem em condições mais favoráveis com domicílios com 4 ou mais banheiros (mapa 9).

Mapa 9 - Domicílios com 4 banheiros ou mais (\%), por setor censitário, na cidade de Campos dos Goytacazes

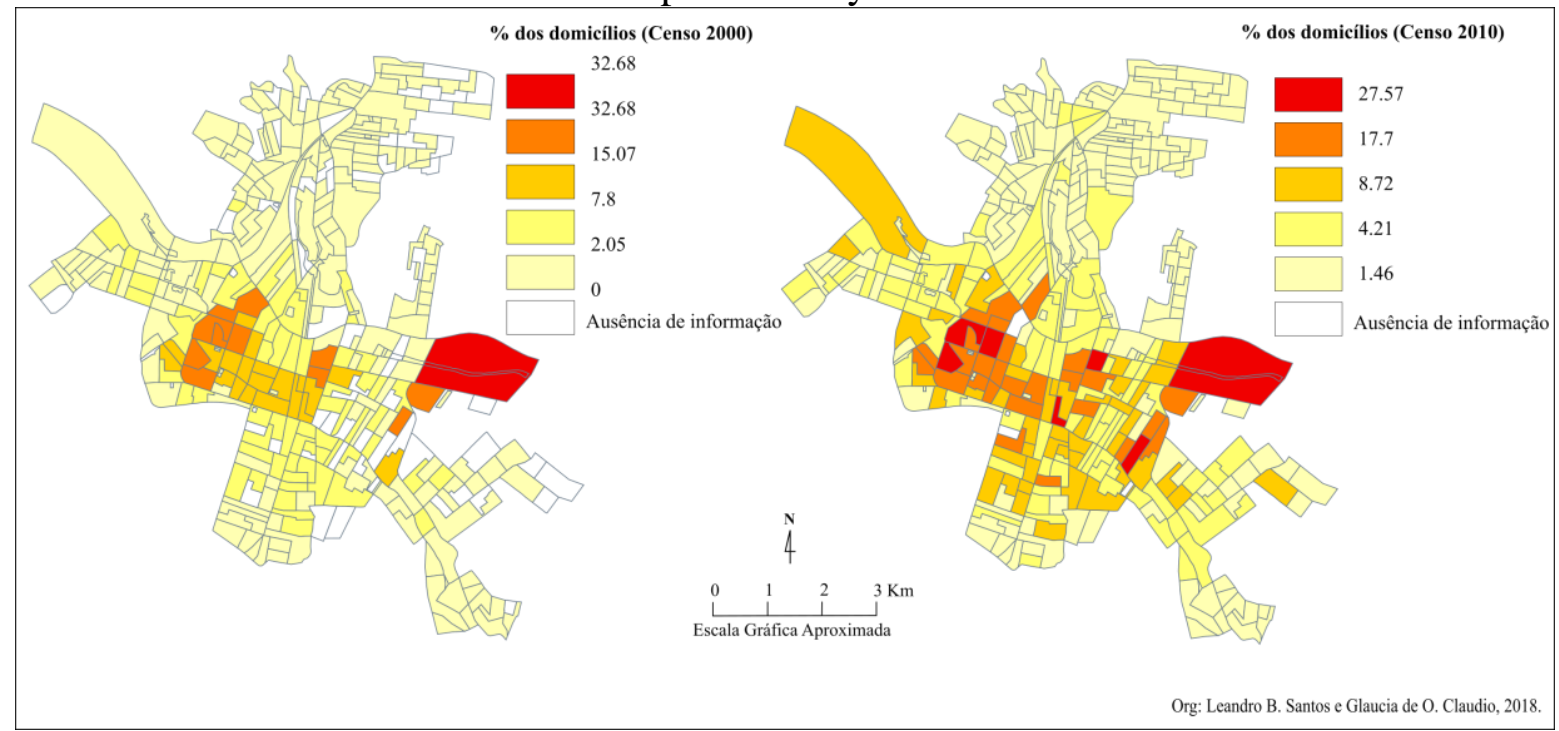

Fonte: Microdados do IBGE (Censos 2000 e 2010)

Essas áreas nobres da cidade, no ano de 2000, estavam concentradas próximas ao centro da cidade, nos bairros Parque Avenida Pelinca, Parque Tamandaré, Jardim Maria Queiroz. A diferença de 2000 para o ano de 2010 pode ser notada pela presença deste padrão dos domicílios com 4 ou mais banheiros situados em setores mais dispersos, na margem direita, entre 8 a $17 \%$ de domicílios. 
CLAUDIO, G. O.; SANTOS, L. B.

Os espaços da exclusão social na cidade de Campos dos Goytacazes - RJ

Isto podendo ser atribuído à forte atuação de setor mobiliário nas últimas décadas. Neste século, temos a construção da Avenida Arthur Bernardes, que se tornou "um corredor de investimentos imobiliários" tanto em relação aos condomínios verticais, como também os condomínios horizontais, de alto-médio padrão, formados no "arco de valorização fundiária" (figura 1), abrangendo os segmentos leste e sudoeste da cidade.

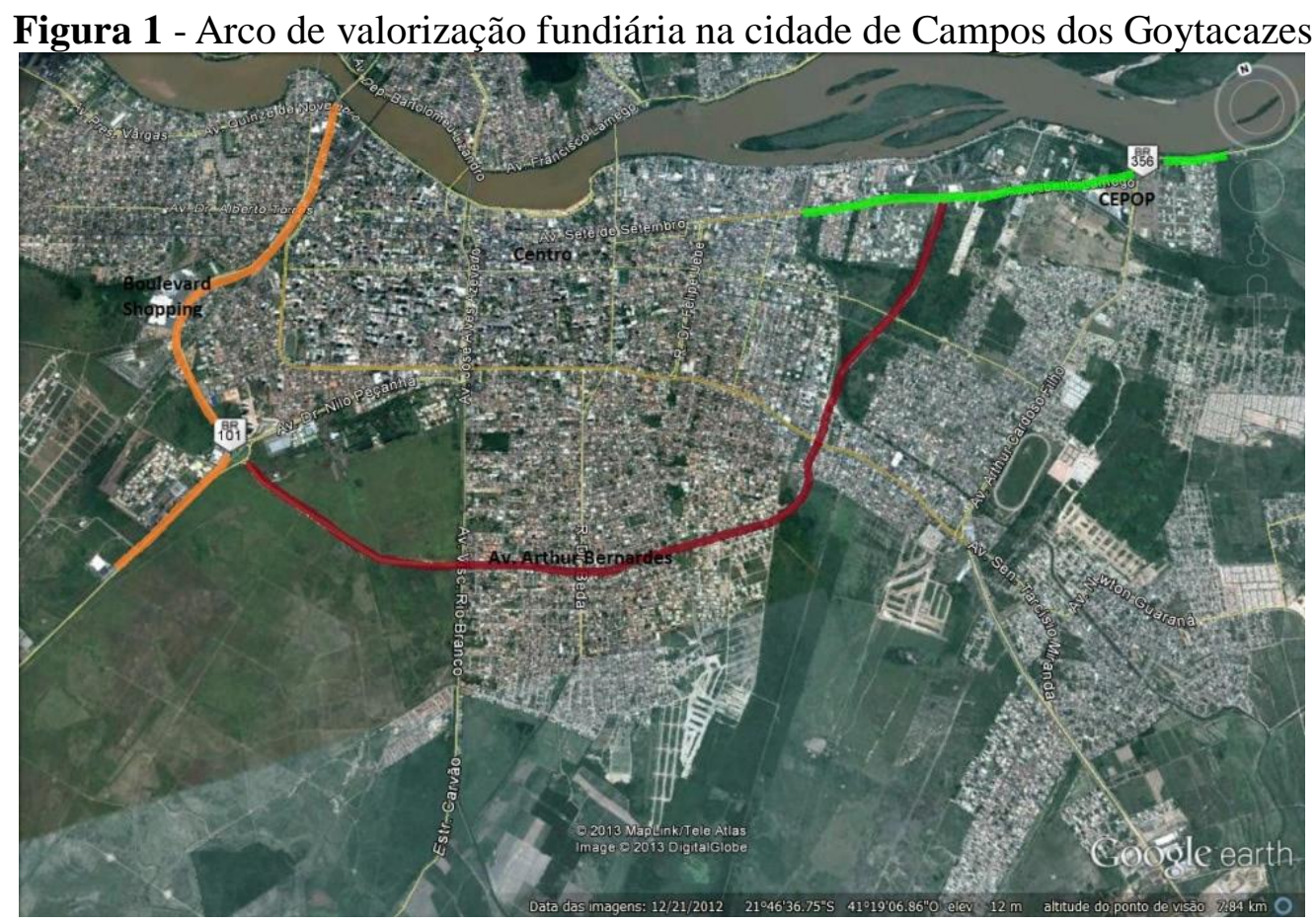

Fonte: GOMES, 2015.

De acordo com Gomes (2015, p. 40), nos interstícios do arco de valorização fundiária,

[...] desenvolve-se uma pluralidade de ocupações: edifícios de apartamentos de variados padrões, com destaque para o surgimento de empreendimentos de mais de 6 pavimentos no bairro Flamboyant; ampliação da ocupação unifamiliar de bairros residenciais por segmentos de renda média, como o Alphaville II; ampliação e diversificação das atividades comerciais etc. Observa-se, dessa forma, um dinamismo crescente em bairros tradicionais como Parque Aurora e IPS e a sinalização do início desse processo no bairro do Jockey, contíguo ao bairro Flamboyant.

Isso nos leva a pensar que não foram apenas processos passados, aqueles presentes no início da expansão urbana, que levaram os investimentos públicos a atender a elite política e econômica da cidade. Alguns investimentos recentes ainda privilegiam áreas centrais da cidade ou eixos de expansão e valorização fundiária, marcados por forte 
CLAUDIO, G. O.; SANTOS, L. B.

Os espaços da exclusão social na cidade de Campos dos Goytacazes - RJ

especulação imobiliária, além de bairros mais afastados da área central, geralmente condomínios horizontais, por conta da atuação conjunta com os investimentos públicos de saneamento e infraestrutura urbana. Enquanto isso, as áreas que não estão inseridas no arco de valorização fundiária da cidade acabam sofrendo com a precariedade dos investimentos públicos em serviços fundamentais, como educação, saúde, segurança pública e mobilidade urbana.

Quanto ao indicador de educação, com a variável de responsáveis por domicílios alfabetizados (mapas 10), o eixo norte da cidade é marcado, no ano de 2000, pela forte concentração de baixa escolaridade de responsáveis por domicílio, cujos chefes possuem poucos anos de estudo. Esse padrão de baixa escolaridade dos chefes de família, no norte da cidade, se mantém no ano de 2010, sendo possível notar, ainda, a mesma tendência nos setores com ausência de informação no ano de 2000. Alguns setores censitários exibiram até 97\% de responsáveis por domicílios alfabetizados no ano de 2010. Notamos também que, em alguns setores, houve a melhora desta variável, como Parque Santo Antônio, Parque São Mateus.

Mapa 10 - Responsáveis por domicílios alfabetizados (\%), por setor censitário, na cidade de Campos dos Goytacazes

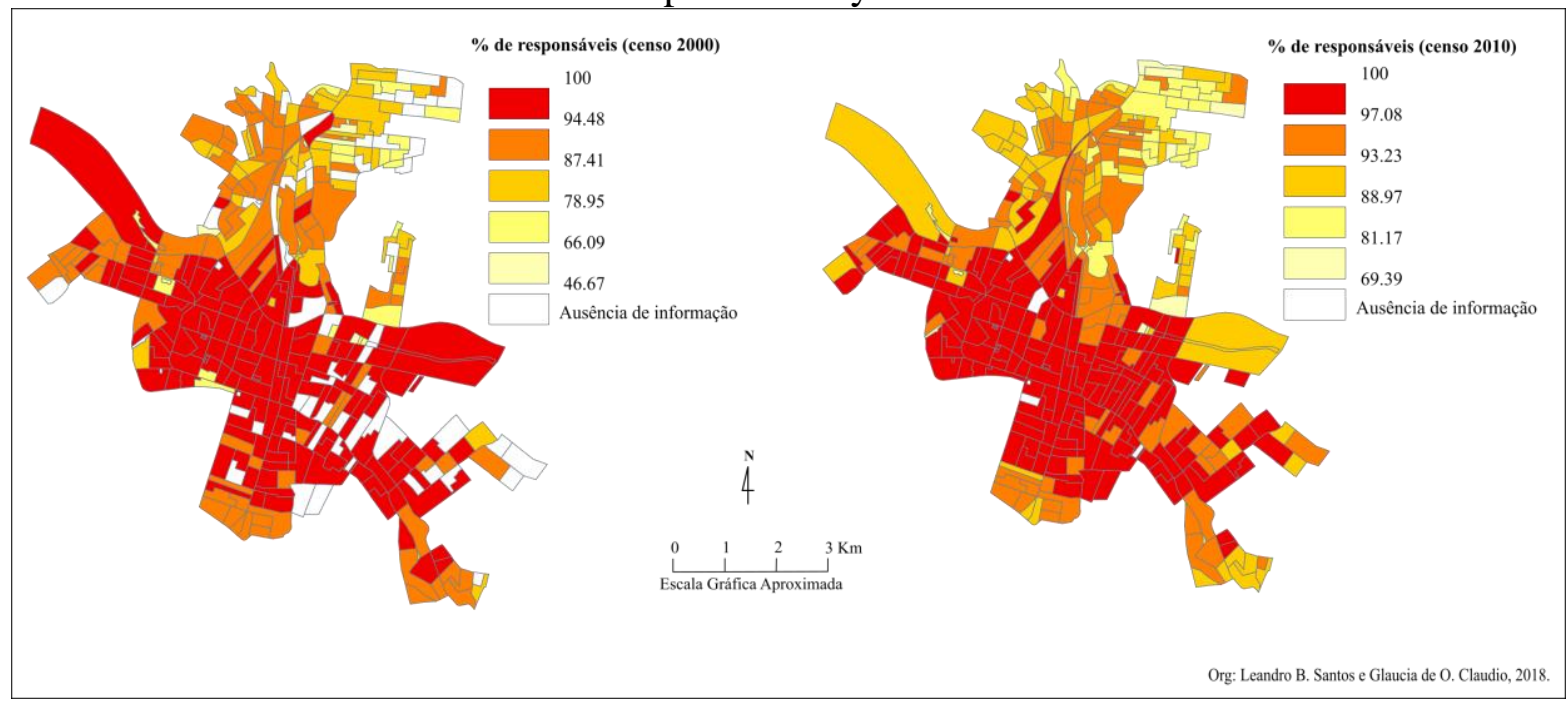

Fonte: Microdados do IBGE (Censos 2000 e 2010)

E o que chama atenção é que, nos setores mais distantes, ocorreu a diminuição desse indicador, com destaque para os bairros Cidade Luz, Parque Guarus, Parque Prazeres e Penha, que apresentavam, no ano de 2000, setores com aproximadamente $95 \%$ dos 
CLAUDIO, G. O.; SANTOS, L. B.

Os espaços da exclusão social na cidade de Campos dos Goytacazes - RJ

responsáveis alfabetizados. No ano de 2010, houve uma redução de $2 \%$ de responsáveis alfabetizados, além de manter o padrão de discrepância entre os setores. Alguns setores apresentaram uma redução de 3\%, sobretudo aqueles situados nos bairros Parque Bonsucesso e Parque Zuza Mota.

Outra variável que merece ser analisada no indicador de educação é a de jovens alfabetizados de 10 a 14 anos (mapa 11). O que podemos perceber é que esta variável segue o mesmo padrão da variável anterior, marcando o baixo índice de alfabetizados ao norte. No ano de 2000, é prevalente o número de setores com até aproximadamente 97\%, enquanto o eixo sul é marcado por uma grande quantidade de setores com até $100 \%$ de jovens de 10 a 14 anos alfabetizados.

Mapa 11 - Jovens de 10 a 14 anos alfabetizados (\%), por setor censitário, na cidade de Campos dos Goytacazes

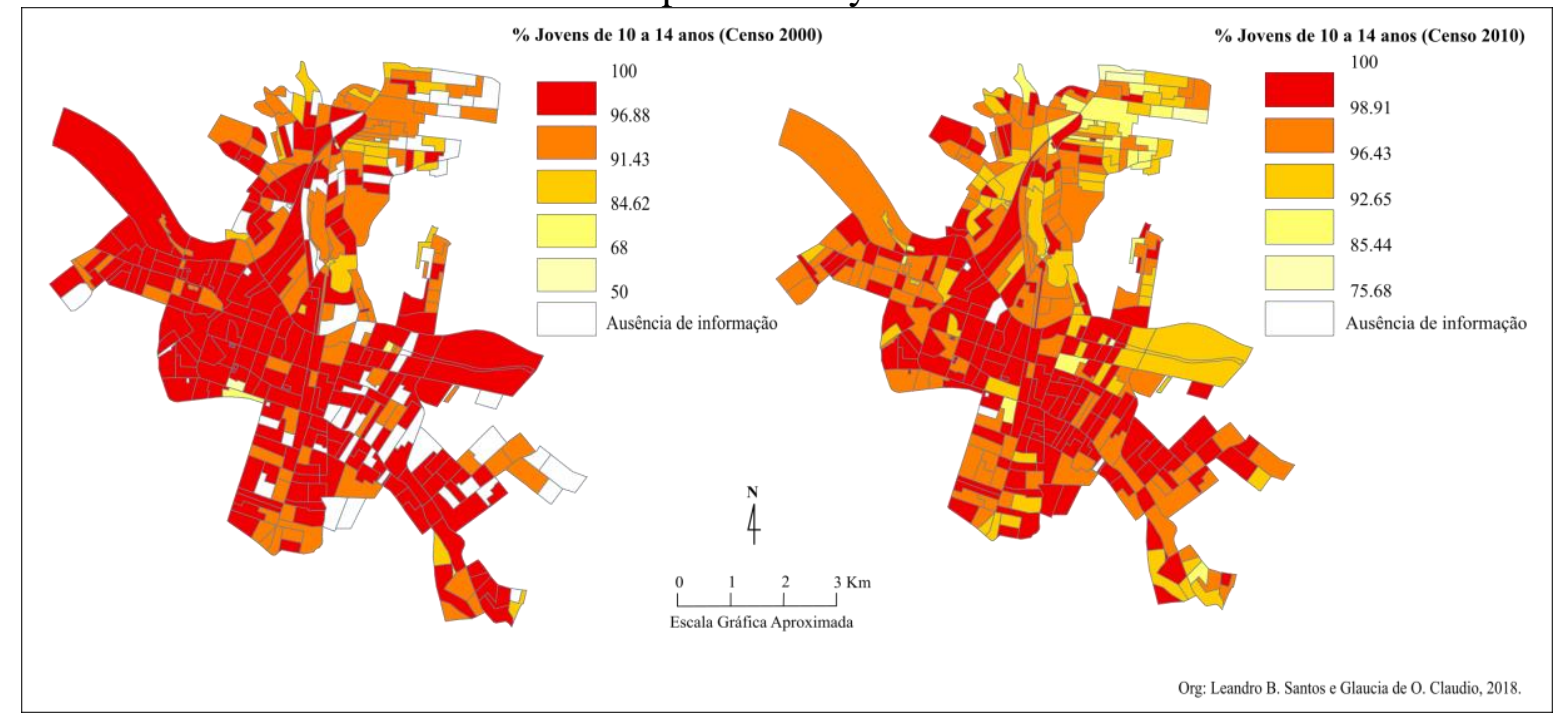

Fonte: Microdados do IBGE (Censos 2000 e 2010)

No ano de 2010, houve o oposto do percentual de responsáveis alfabetizados, marcando o aumento de 3\% do percentual de jovens de 10 a 14 anos alfabetizados, como é o caso do bairro Barão do Rio Branco. Os setores que apresentam a diminuição de percentual de jovens alfabetizados podem ser localizados nos bairros Parque São Silvestre, Parque Eldorado, Vila Industrial, Parque Santa Rosa e Parque São Domingos. O que chama atenção nesta variável é que, ao analisarmos conjuntamente com o índice de criminalidade, as áreas que apresentam o baixo percentual dos jovens alfabetizados são as mesmas que apresentam elevado índice de violência contra adolescentes e jovens. 
CLAUDIO, G. O.; SANTOS, L. B.

Os espaços da exclusão social na cidade de Campos dos Goytacazes - RJ

Vemos, ainda, que a concentração de baixa escolaridade situada nos bairros citados acima condiz com as áreas de homicídios de jovens e adolescentes, onde se concentram 19\% (figura 2) dos homicídios na cidade de Campos. Isso remete a condições de segurança pública, mas principalmente à ausência de políticas públicas no que tange o acesso dos jovens à educação. Grande parte dos setores censitários situados mais ao norte da cidade é marcada por índices elevados de ausências de toda sorte, como acesso à rede de esgoto, banheiros nos domicílios, baixa escolaridade dos chefes de famílias e de jovens de 10 a 14 anos, baixa ou ausência de renda, número elevado de pessoas por domicílio, entre outras.

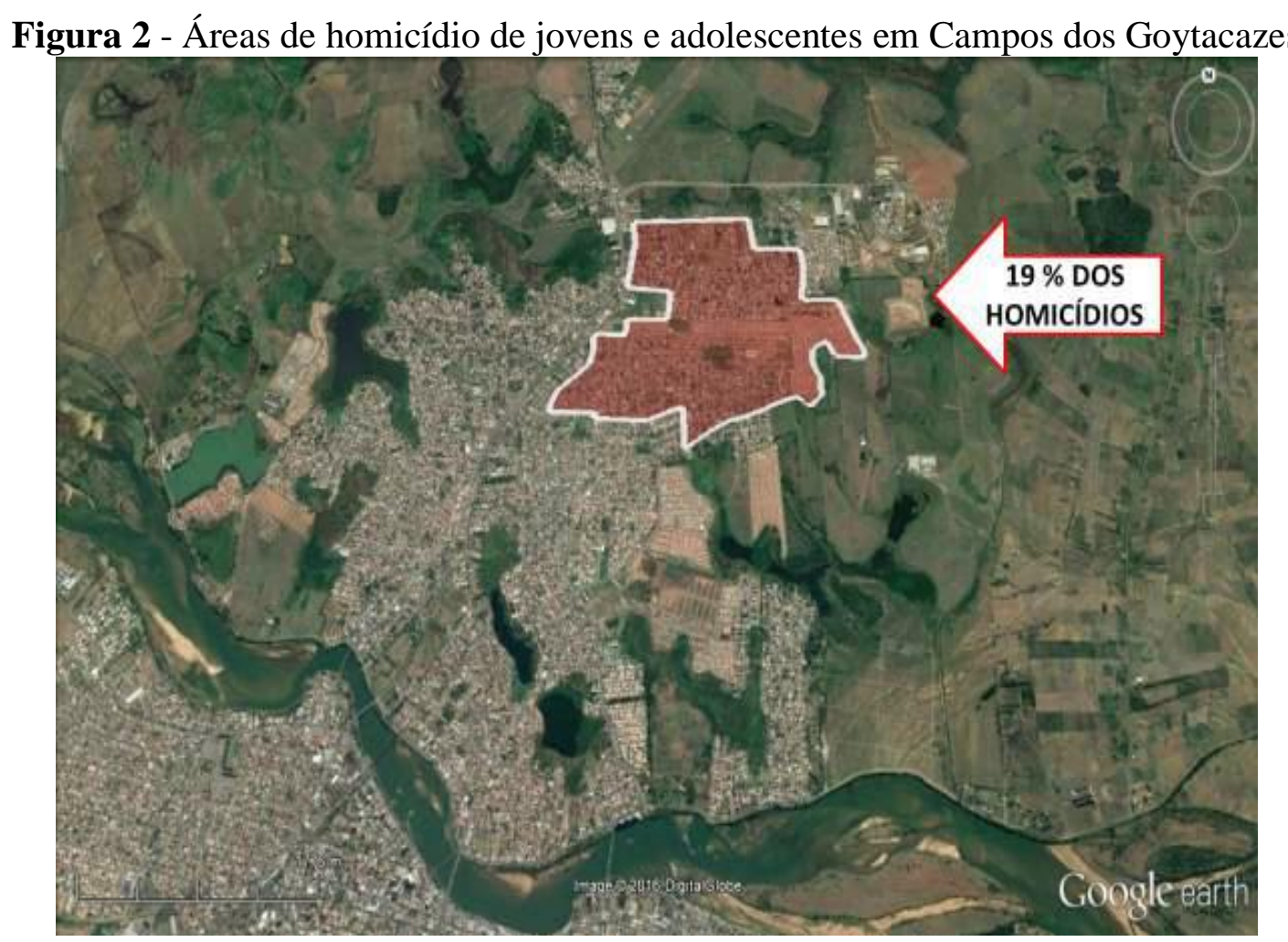

Fonte: Perfil campos 2018.

Quando falamos em exclusão social em Campos dos Goytacazes, estamos nos referindo a uma sobreposição de diversas ausências, que acometem as condições de existência de parcela considerável da população. Os espaços da exclusão social, onde temos uma sobreposição das variáveis analisadas, estão concentrados no extremo norte do município e nas franjas do tecido urbano. 


\section{CONSIDERAÇÕES FINAIS}

A discussão da exclusão social permite, não só analisar os impactos que circundam a desigualdade, senão também identificar as matrizes excludentes e como elas influenciam a vida das pessoas e nas formas como os grupos interagem uns com os outros. Além disso, permite identificar quais áreas sofrem com a falta ou precariedade dos equipamentos públicos de uso coletivo, como saneamento, escolas, segurança, a fim de auxiliar na contribuição de políticas públicas, a partir do momento que se tem uma identificação de onde estão situadas as áreas que merecem um investimento maciço em equipamentos públicos de uso coletivo.

Sendo assim, trata-se de uma noção [exclusão social] que merece ser estudada e reconhecida pela própria população, pois, a partir do momento que o sujeito se reconhece como excluído de algum serviço ou de algum direito, é que o mesmo passa a adquirir voz para buscar lutar pelo seu espaço como cidadão e não mais apenas como consumidor, mas sim como possuidor de consciência de classe. Entender a exclusão é vê-la imbricada com a cidadania, pois não se pode falar de cidadania sem falar no direito que a sociedade tem de usufruir não apenas da cidade como espaço habitado, senão de todos os direitos considerados essenciais para que se haja cidadania.

Podemos perceber que os processos de exclusão social não ocorrem de forma homogênea tanto na escala da cidade como dentro dos próprios bairros, com a presença de discrepâncias de setores censitários com relação às variáveis analisadas. Esse processo não ocorre de forma homogênea por conta da forte atuação do setor imobiliário na cidade, que tem contribuído para a desigualdade socioespacial. Na cidade de Campos dos Goytacazes, notamos os traços dessa exclusão social principalmente no lado norte do Rio Paraíba do Sul.

Se fizermos uma sobreposição dos indicadores, notaremos que os mesmos setores que apresentam baixos percentuais de responsáveis alfabetizados são aqueles que apresentam grandes famílias numerosas, com baixa renda e sem acesso a rede de esgoto. Na cidade de Campos, esses setores estão situados no Parque Eldorado, Parque Guarus, Parque Prazeres, Parque Cidade Luz, Vila Industrial, Parque São Silvestre, entre outros, situados ao norte da cidade. Além de apresentar um forte grau de exclusão social na escala intraurbana, também exibem diferentes níveis de exclusão dentro dos próprios setores censitários. 


\section{REFERÊNCIAS}

ATLASBRASIL. Atlas do Desenvolvimento Humano no Brasil. Perfil Campos dos Goytacazes - RJ. Disponível em: <http://atlasbrasil.org.br/2013/pt/>. Acesso em: 26 de Junho de 2018.

BRENNER, N.; PECK, J.; THEODORE, N. Após a neoliberalização? Cadernos Metrópole. São Paulo, v. 13, n. 26, p. 15-39, 2012.

CARVALHO, E. Exclusão social e crescimento das cidades médias brasileiras. Scripta Nova - Revista electrónica de geografía y ciencias sociales. Barcelona: Universidad de Barcelona, v. VII, n. 146, s.p., 2003.

GOMES, M. A. S. A produção e a valorização desigual do espaço urbano em Campos dos Goytacazes-RJ: uma análise das ações do Estado e dos promotores/incorporadores imobiliários. Geografares, n. 15, p. 28-41, Jan/Jul. 2015.

IBGE - Instituto Brasileiro de Geografia e Estatística. Censo 2010. Disponível em: <http://www.censo2010.ibge.gov.br/sinopse/index.php?uf=33\&dados=1 > Acesso em: $12 \mathrm{de}$ setembro, 2017.

IPEA. A Década Inclusiva (2001-2011): Desigualdade, Pobreza e Políticas de Renda. Brasília: Secretaria de Assuntos Estratégicos da Presidência da República, 2012.

MARTINUCI, O. S. Mapeamento e análise das desigualdades territoriais em cidades de porte médio do interior do Paraná. Maringá: UEM, 2016 (mimeo).

MARTINS, J. S. Exclusão social e a nova desigualdade. São Paulo: Paulus, 1997.

A sociedade vista do abismo. Petrópolis: vozes, 2002.

MELAZZO, E. S.; GUIMARÃES, R. B. Exclusão social em cidades brasileiras: um desafio para as políticas públicas. Editora Unesp, 2010.

PNUD. O que é IDHM. Disponível em: <http://www.br.undp.org/content/brazil/pt/ho me/idh0/conceitos/o-que-e-o-idhm.html> Acesso em: 25 de Junho de 2018.

PREFEITURA DE CAMPOS DOS GOYTACAZES. PERFIL 2018. Disponível em: <https://www.campos.rj.gov.br/newdocs/1542233062PERFILCAMPOS2018.pdf> Aces so em: 14 de Novembro de 2018.

SANTOS, M. Por uma outra globalização. Rio de janeiro: Record, 2000.

. O Espaço do Cidadão. $7^{\text {a }}$ edição. São Paulo: Edusp, 2007.

SCHWARTZMAN, S. As causas da pobreza. Rio de Janeiro: FGV. 2004. 
SMITH, N. Desenvolvimento desigual: natureza, capital e produção do espaço. Rio de Janeiro: Bertrand Brasil, 1988.

SINGER, P. Globalização e desemprego: diagnóstico e alternativas. São Paulo. Contexto, 1999.

SPOSITO, M. E. B. Novos conteúdos das periferias urbanas das cidades médias do estado de São Paulo, Brasil. Investigaciones Geográficas, Cidade do México, n. 54, p. 114-139, 2004.

VIEIRA, A. B. Mapeamento da exclusão social em cidades médias: interfaces da Geografia Econômica com a Geografia Política. 194 f. 2009. Tese (Doutorado em Geografia), Faculdade de Ciências e Tecnologia, UNESP, 2009.

\section{Autores}

Glaucia de Oliveira Claudio - Possui Graduação em Geografia pela Universidade Federal Fluminense (UFF/Campos dos Goytacazes).

Leandro Bruno Santos - Possui Graduação, Mestrado e Doutorado em Geografia pela Universidade Estadual Paulista Júlio de Mesquita Filho (UNESP). Realizou doutorado sanduíche na Facultad de Economía, da Universidad Autónoma de Puebla (BUAP). Atualmente é Professor dos Cursos de Graduação em Geografia e do Programa de PósGraduação em Geografia da Universidade Federal Fluminense - UFF. É bolsista Jovem Cientista do Nosso Estado pela Fundação Carlos Chagas Filho de Amparo à Pesquisa do Estado do Rio de Janeiro (FAPERJ).

Artigo recebido em: 24 de julho de 2019.

Artigo aceito em: 15 de setembro de 2019. Artigo publicado em: 16 de setembro de 2019. 